\title{
OSSERVAZIONI SISMICHE E CLINOGRAFICHE PRESSO GRANDI DIGHE DI SBARRAMENTO
}

\author{
Piftro Caloi
}

1. - Il progresso nella scienza è reso possibile solo da un continuo affinamento delle ricerche: soltanto mutando via via $\mathrm{i}$ metodi d'indagine, rendendoli sempre più sottili, profondi e penetranti, è consentito progredire nel problema della conoscenza.

Non solo si deve tendere a limitare al minimo, se non ad escludere, l'osservazione diretta (i nostri sensi sono fallaci), ma sostituire progressivamente l'osservazione mediata, saltuaria personale, con l'osservazione continua strumentale.

Noi dobbiamo abituarci a scendere nell'intimo della materia; non limilarsi alle sue più o meno vistose manifestazioni esterne. Queste non sono che il riflesso di fenomeni che hanno un'origine ben più riposta: e dagli efletti di superficie non sempre è agevole risalire alle cause. Cosi, dobbiamo spostare la nostra attenzione dalle grandi oscillazioni, dai grandi spostamenti, alle microoscillazioni, ai microspostamenti: dai grandi sbalzi di temperatura, di tensione elastica, di pressione, ecc. dobbiamo affinare il nostro spirito d'indagine per scendere alla microstruttura della materia, apparentemente in quiete e alle sue micromanilestazioni.

Qui sta il segreto di ogni fenomeno, la fonte di ogni esterna manifestazione. $\grave{E}$ nella quiete apparente che maturano i grandi sconvolgimenti : quando cominciano a manifestarsi in modo sensibile, è quasi sempre troppo tardi per dominarli: bisogna saper sorprenderli nella loro fase di preparazione, quando tutto sembra tranquillo.

2. - Di qui, come si è detto, la necessità di una continua, minutissima sorveglianza.

Prendiamo a considerare, ad esempio, i moti lenti della crosta terrestre. La Geodesia ha i mezzi per poter fare, con notevole precisione, livellazioni e triangolazioni. Il geodeta compie però le sue precisissime indagini per scopi particolari, e nei luoghi e nei tempi più disparati: talvolta passano decenni prima che una campagna di mi- 
sure geodetiche si ripeta in uno stesso luogo. Ai fini di una efficace interpretazione dei moti lenti della crosta terrestre, ciò è naturalmente insufficiente. Bisogna moltiplicare queste indagini nel tempo e nello spazio; non solo, ma occorre trovare il modo di sostituire all'osservazione personale, la registrazione strumentale conlinua. Solo così potremo seguire con continuità i movimenti di una data regione; solo per questa via sarà possibile spiare ora per ora, minuto per minuto, il comportamento di una zona apparentemente tranquilla; solo in questo modo ci sarà dato di poter sorprendere il momento in cui i moti

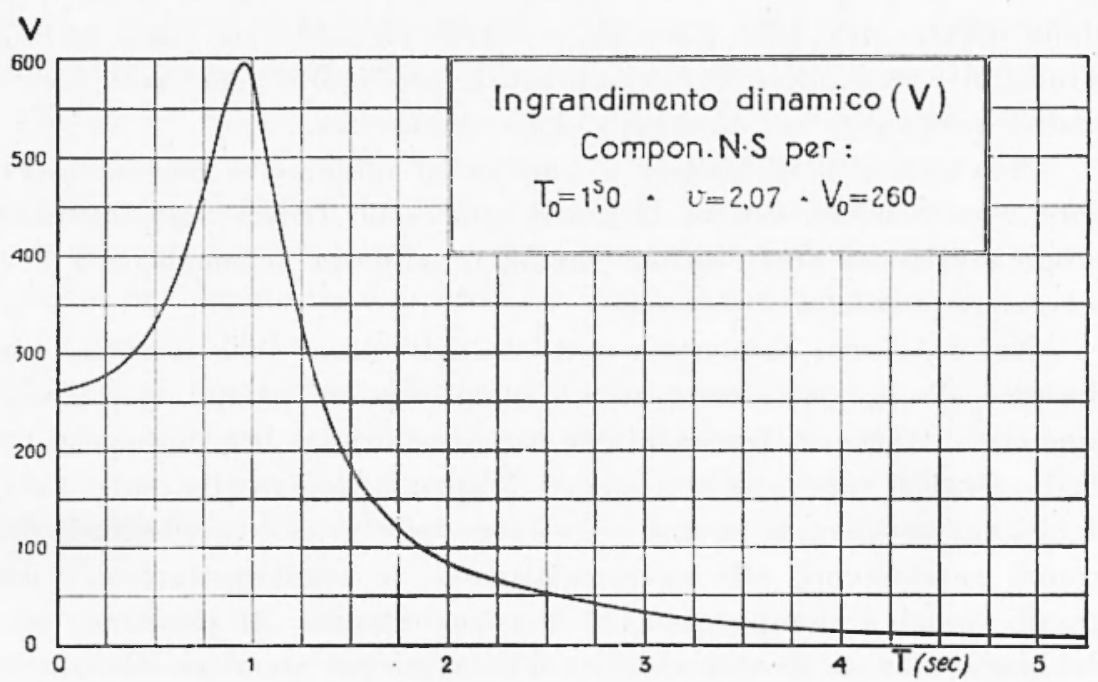

Fig. 1

da microscopici si fanno macroscopici. Captato questo momento, potremo investigare come un'attività impercettibile tenda a farsi vieppiù manifesta; ed una volta conosciuto il come sarà più agevole pervenire anche al perché.

3. - Questo orientamento nelle indagini può avere il suo interesse anche in campi più ristrelti, come può essere quello del comportamento di una grande diga di sharramento per bacini idroelettrici.

I'interesse scientifico ha qui riflessi spiccatamente umani.

Molte sono le cause clie possono nuocere alla stabilita di una diga.

Non entra nel mio compito il catalogarle e il soffermarmi su di esse. Voglio qui solo accennare ad una delle forze che possono deter- 


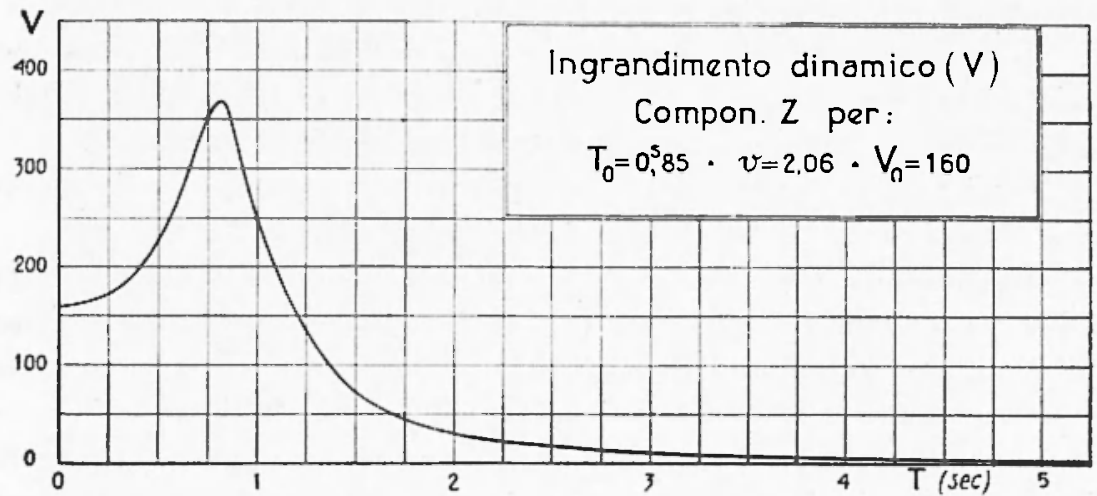

Fig. 2

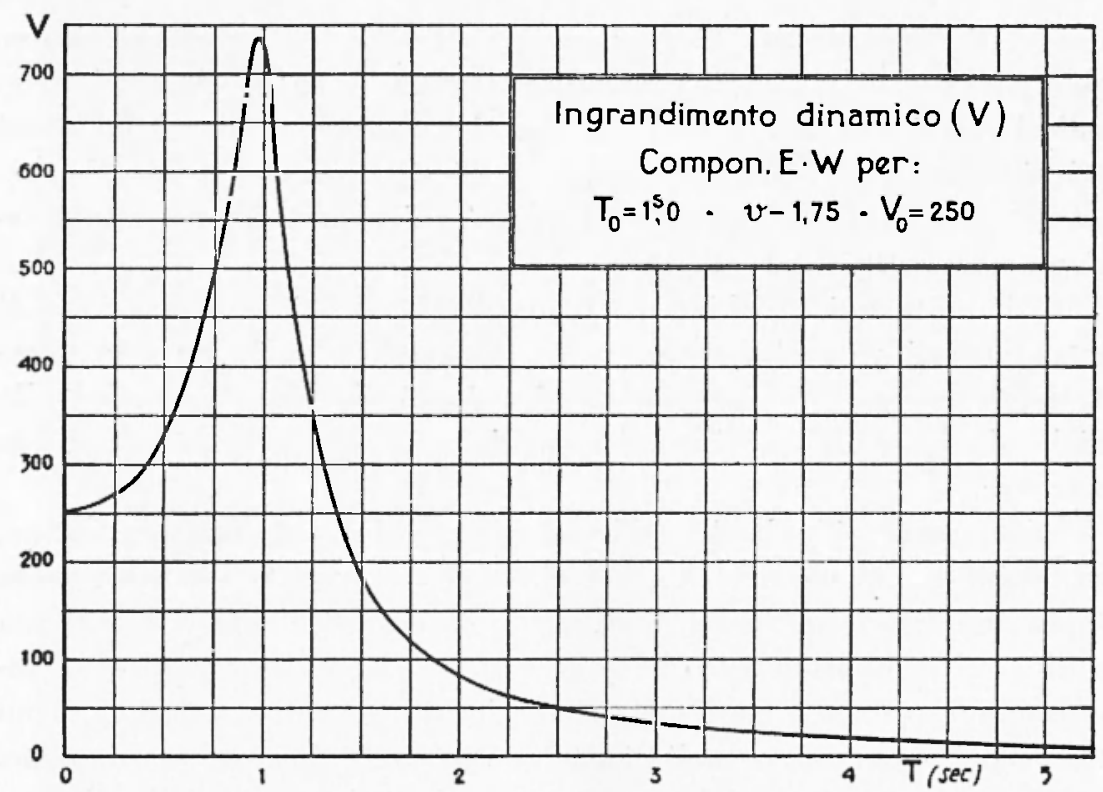

Fig. 3 
minare i massimi danni ad una diga: quella sprigionata dai bruschi movimenti del suolo che la sopportano.

L’ingegnere valuta, nel suo progetto, i carichi e le spinte, ma non può presumere di controbilanciare l'intensità delle forze naturali, quando esse si manifestano associate a fenomeni di risonanza.

Ogni tecnica umana vien meno contro il terremoto, quando il terreno su cui si costruisce è di costituzione infida.

La questione non si esaurisce quindi nel solo ambito della scienza delle costruzioni. C’è tutta una serie di rapporti di dipendenza fra gli effetti del terremoto e il terreno su cui si costruisce. E necessario conoscere appieno le caratteristiche geologiche ed elastiche delle stratificazioni superficiali terrestri, le frequenze proprie predominanti di dette stratificazioni ecc., allo scopo di assegnare ad ogni singola zona il tipo di diga che più le si adatta.

E inoltre del tutto insufficiente considerare il problema soltanto dal punto di vista statico; insufficiente e, molto spesso, erroneo. Senza dubbio, la trattazione dinamica del problema si presenta ardua; ma non ci si deve illudere di aver superato l'ostacolo, quando si ricorre all'espediente di sostituire convenzionalmente le azioni dinamiche con sollecitazioni puramente statiche, che si ritengono produrre gli stessi effetti. Finché gli elementi fondamentali delle azioni dinamiche restano sconosciuti, ogni presunta legge d'equivalenza è pura estrapolazione non autorizzata.

Mi limito qui a richiamare il problema, su cui ebbi oceasione di intrattenermi più a lungo in un precedente lavoro $\left({ }^{1}\right)$. Su esso ritornerò brevemente, quando tratterò dei danni che possono venire alle dighe da parte dei movimenti lenti, dei quali è pure sede la crosta terrestre.

Comunque si veda il problema, è certo che una stazione sismica, costituita di una terna di apparerchi opportunamente costruiti, posta sopra una diga o nei pressi di essa, può dare degli elementi di estrema utilità sul comportamento della diga stessa. Basterà accennare all'interesse del confronto fra le agitazioni che si otterranno a bacino pieno e a bacino vuoto, nei periodi di siccita e in quelli di piogge prolungate.

I movimenti lenti del bacino - e quindi dei conci della diga saranno meglio studiati con dei clinometri. Questi movimenti però, data l'imperfetta elasticità della roccia, sul cui comportamento influiscono pure altre caratteristiche fisiche - quali l'attrito interno e la viscosità -, sono sempre accompagnati da movimenti bruschi, sotto forma di piccole scosse. Ecco la grande importanza di una stazione 


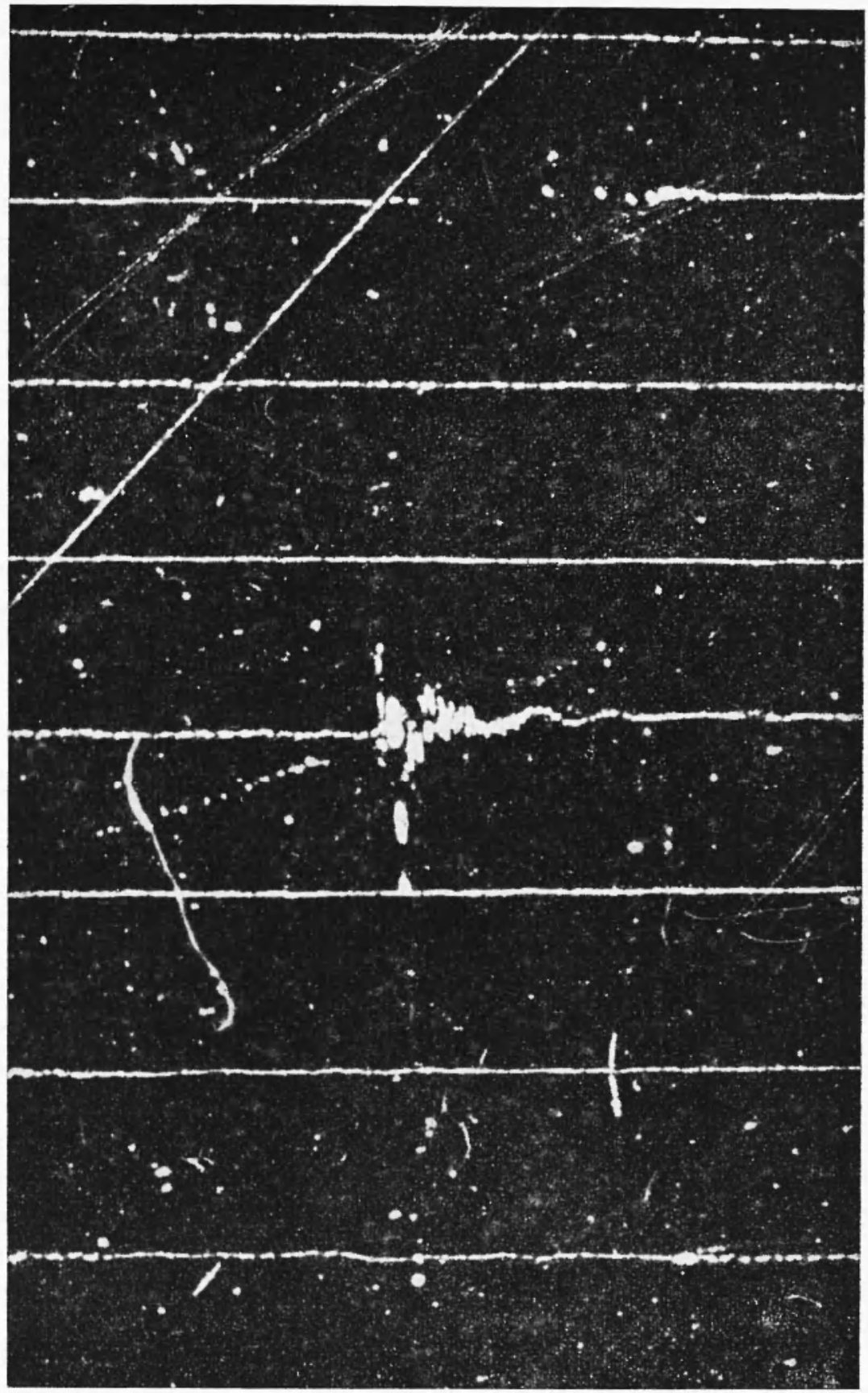

Fig. 4 - Scossetta valutata di III $\left(E=2-10^{12}\right.$ erg ca). Ingrandinento dell'originale 12 volte cirri. 
sismica locale. L'osservazione dirà se c'è stata deformazione elastica (indipendente dal tempo) o deformazione di massa (funzione del tempo); e in quest'ultimo caso, se la deformazione è stata temporanea o permanente (a questa funzione naturalmente risponde meglio l'uso del clinometro).

Anche lo studio delle vibrazioni che concernono i conci della diga si presenta di notevole interesse. E chiaro che esse presenteranno caratteristiche diverse a seconda dello stato dell'invaso e dello stato di tensione cui la diga stessa ̀̀ sottoposta. Queste registrazioni avranno aspetto costante se le tensioni elastiche della diga non subiscono sensibili variazioni, mentre nel caso di una variazione di carico o d'una eventuale lesione esse presenteranno caratteristiche diverse.

Una cosa è certa: non potranno prodursi nella diga lesioni, per quanto piccole, ch'esse non siano prontamente registrate nei diagrammi sismici.

Grazie ai sismografi e ai fotoclinometri, la sorveglianza delle dighe diventerà automatica. Fra l'altro, i documenti da essi forniti costituiranno altrettante irrefutabili testimonianze per la verità e la giustizia.

\section{4. - Moti lenti della crosta terrestre: blocchi geodetici.}

É noto che la crosta terrestre è sede di lenti movimenti di ascesa o di discesa rispetto al medio livello dei mari; movimenti che possono far sorgere dal mare regioni, più o meno estese, un tempo sommerse o provocare la sommersione di zone rivierasche continentali, un tempo emerse. Questi moti si manifestano naturalmente in tempi lunghissimi e vanno sotto la denominazione generica di "variazioni secolari " $\left({ }^{2}\right)$.

É stato provato, di recente, che ai movimenti di carattere generale interessanti una regione, sono sovrapposti dei moti particolari, specifici di parti limitate della crosta terrestre $\left(^{2}\right)$. Tali movimenti furono messi in evidenza mediante la frequente ripetizione di misure geodetiche di precisione in una stessa zona; anche le osservazioni clinografiche servono ottimamente a questo scopo. Si è così trovato che settori di crosta terrestre, limitati da giovani faglie, sono soggetti in blocco a movimenti di ascesa o discesa, senza esserne sensibilmente deformati.

Ritengo che tale fenomeno rivesta un particolare interesse nelle questioni relative alla stabilità di una diga.

Constatata la realtà della suddivisione della crosta terrestre in 


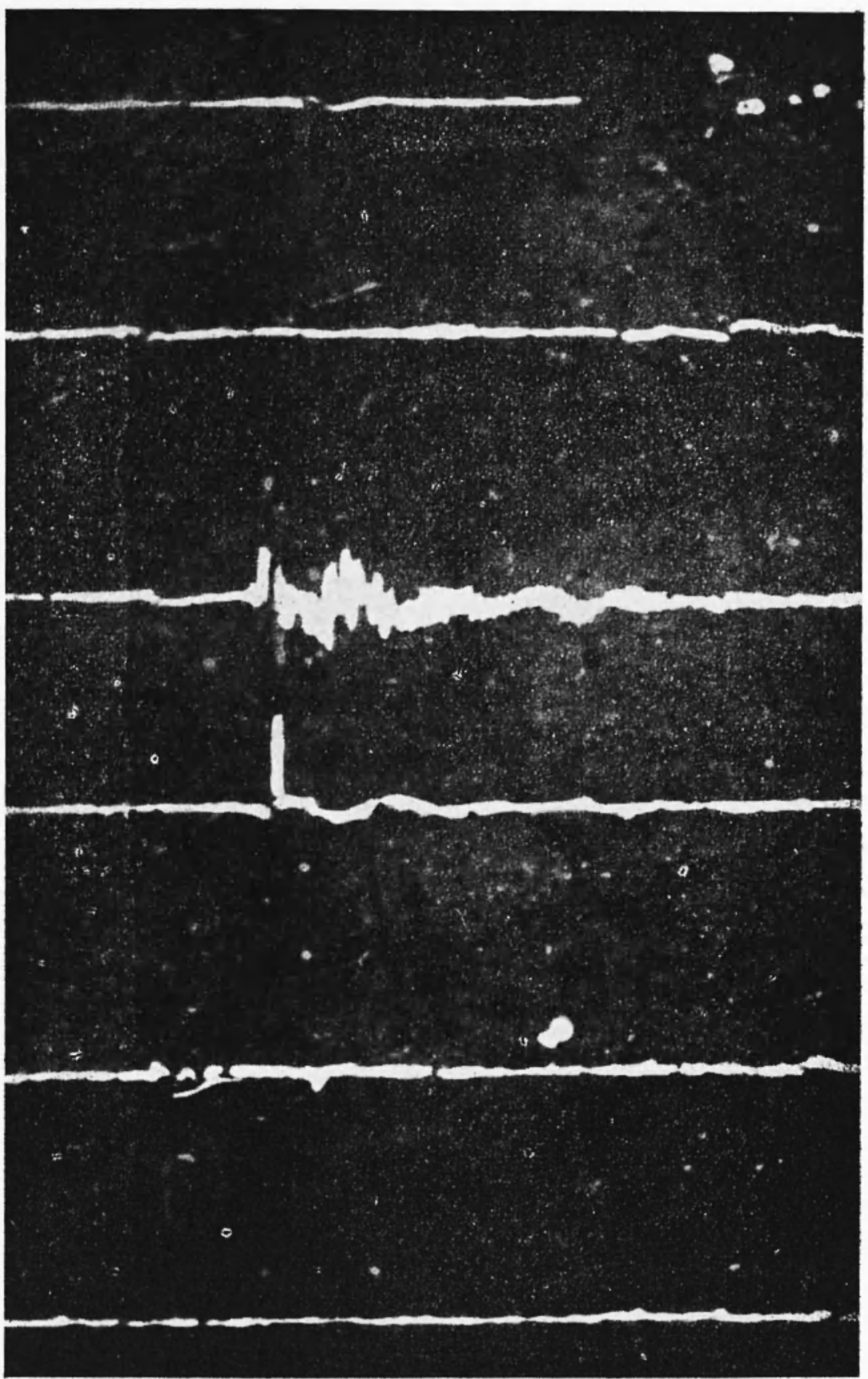

Fig. 5 - Scossetta valutata di II $\left(E=3.10^{11}\right.$ erg ca). 


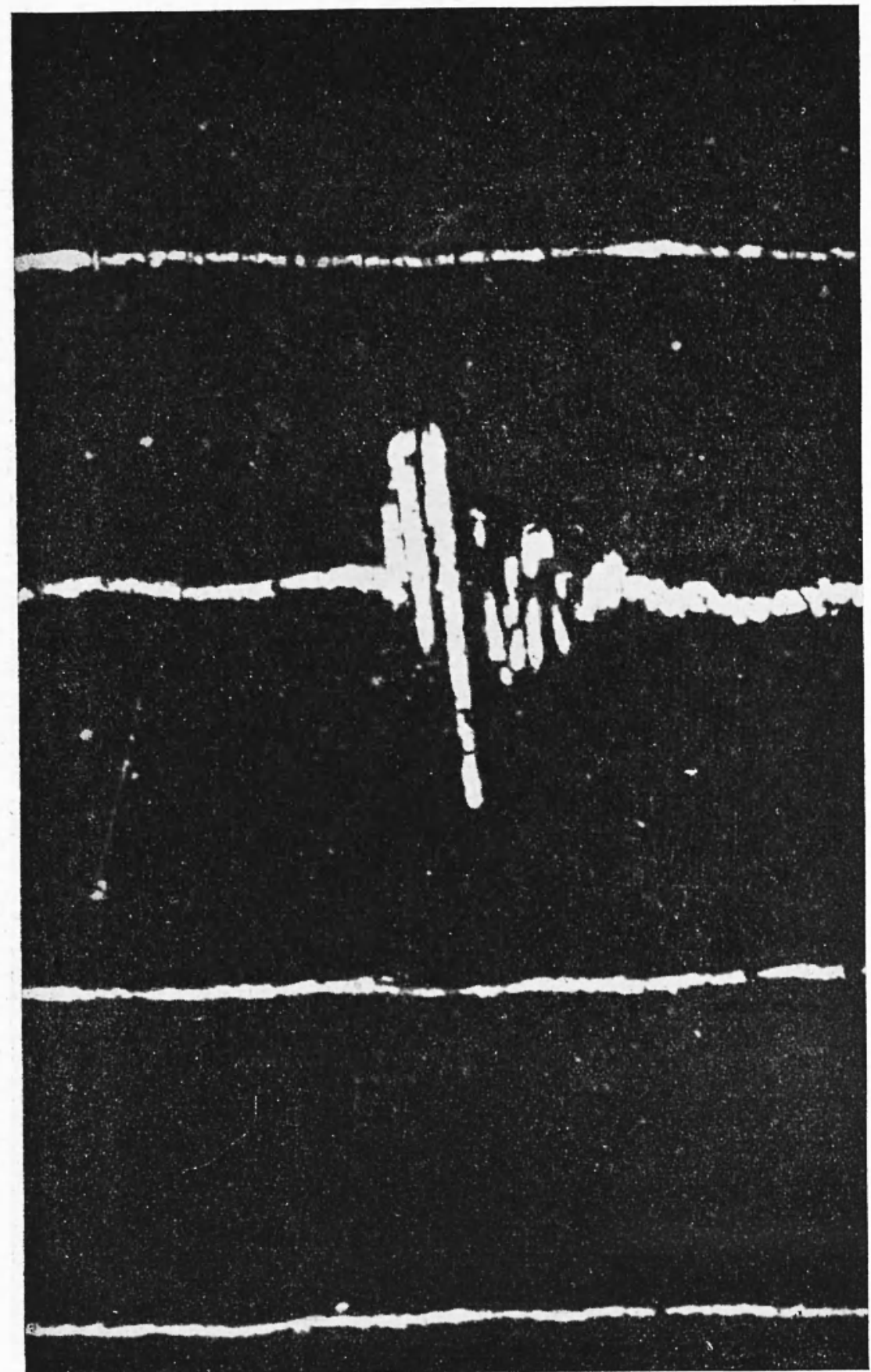

Fig. 6 - Scossetta valutata di II $\left(\mathrm{E}=10^{11}\right.$ erg ea). Ingrandimento 25 volte circa dell'originale. 
blocchi, è di capitale importanza evitare che una diga venga a trovarsi a cavalcioni delle zone divisorie di due blocchi.

Movimenti di questi ultimi di segno contrario - o anche dello stesso segno ma di ampiezze diverse - possono riuscire pericolosi per la stabilità di una diga.

Esistono metodi che consentono la delimitazione degli eventuali blocchi geodetici, propri di una zona.

Uno dei più efficaci, è l'uso di fotoclinometri posti sulle sponde opposte di un fiume, nella zona dove è prevista la costruzione di una diga di sbarramento. Le registrazioni continue, ottenute in un congruo lasso di tempo, permetteranno di stabilire se le sponde in parola partecipano di un solo blocco geodetico o di due blocchi limitrofi.

5. - L'Ufficio Studi di una grande Società idroelettrica, diretto da un autentico scienziato, si rese conto dell'interesse che osservazioni sismiche e clinografiche, ottenute presso grandi dighe, potevano presentare.

Dietro suo invito, il nostro Istituto provvide all'installazione di opportune stazioni sismiche e foloclinografiche presso una grande diga pressoché ultimata; stazioni clinografiche furono successivamente sistemate presso altri bacini idroelettrici della stessa Società.

Riassumerò qui brevemente alcuni dei risultati ottenuti.

Le relative relazioni dettagliate sono in possesso della Societa, che le esaminerà ai fini di una loro utilizzazione: sono pertanto tuttora di carattere riservato.

Alcune caratteristiche di interesse generale possono comunque essere fin d'ora rese note.

Cominciamo dalle osservazioni sismiche.

I sismografi, costruiti nelle officine dell'Istituto Nazionale di Geofisica sotto la direzione del geofisico dott. Peronaci, sono a registrazione meccanica. Le principali caratteristiche strumentali sono riportate nelle figg. 1, 2, 3. L'ingrandimento si è dovuto tenere entro limiti ridotti, data la vicinanza dell'origine dei fenomeni da registrare. Presso la diga, in un primo momento, fu messa una tema di strumenti (comp. verticale; comp. N.S e comp. E-W); un altro strumento (comp. N-S), fu messo a funzionare arl una distanza di $2 \mathrm{~km}$ ca.

Attualmente, tutti e quattro gli strumenti funzionano presso la diga.

Terminata la diga, a mano a mano che il bacino veniva riempiendosi d'acqua, si cbbe la registrazione di minutissime, piccole scos- 


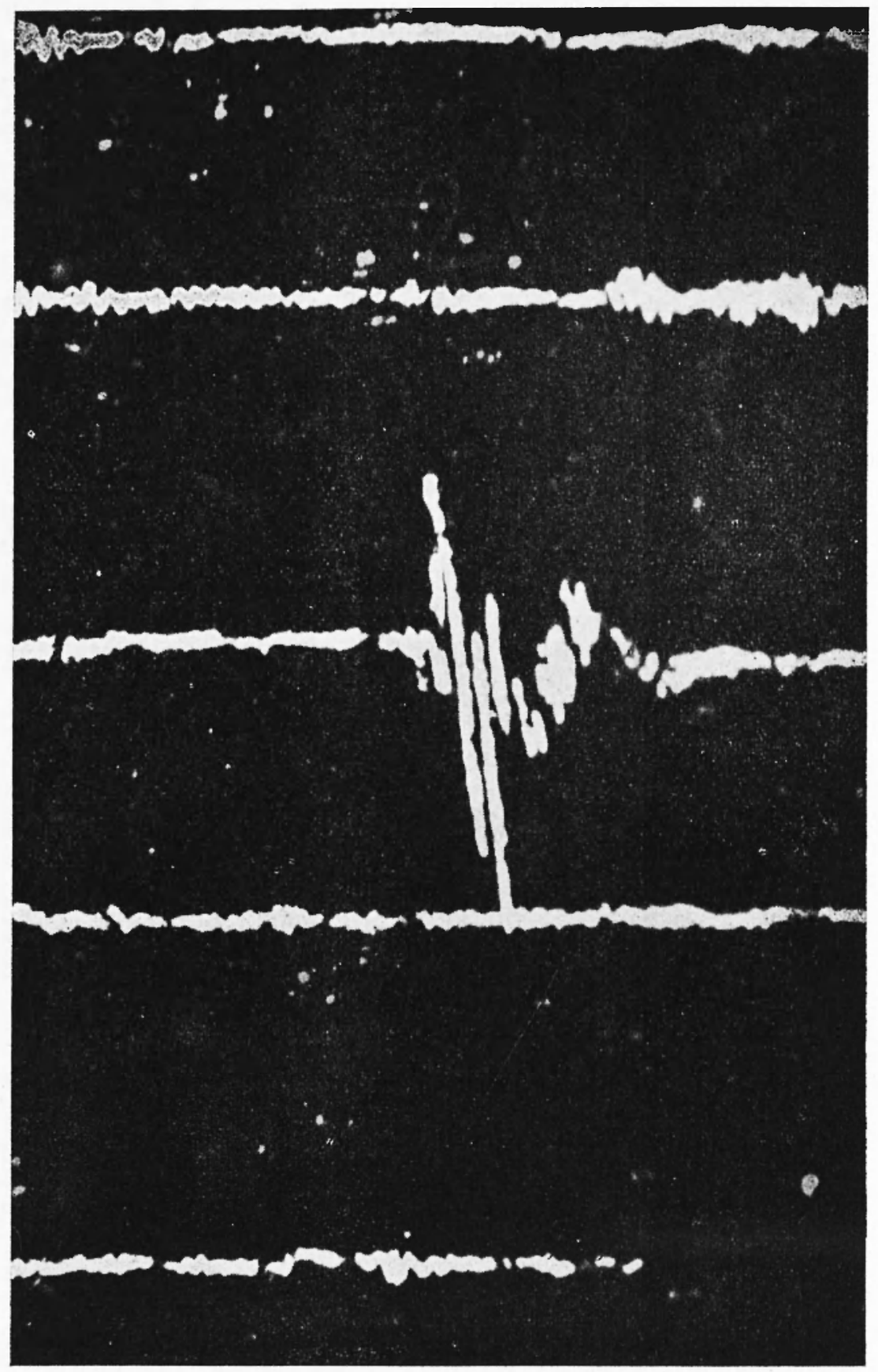

Fig. 7 - Scossetta valutata di II ( $E=1,5 \cdot 10^{11} \mathrm{erg}$ ca). 


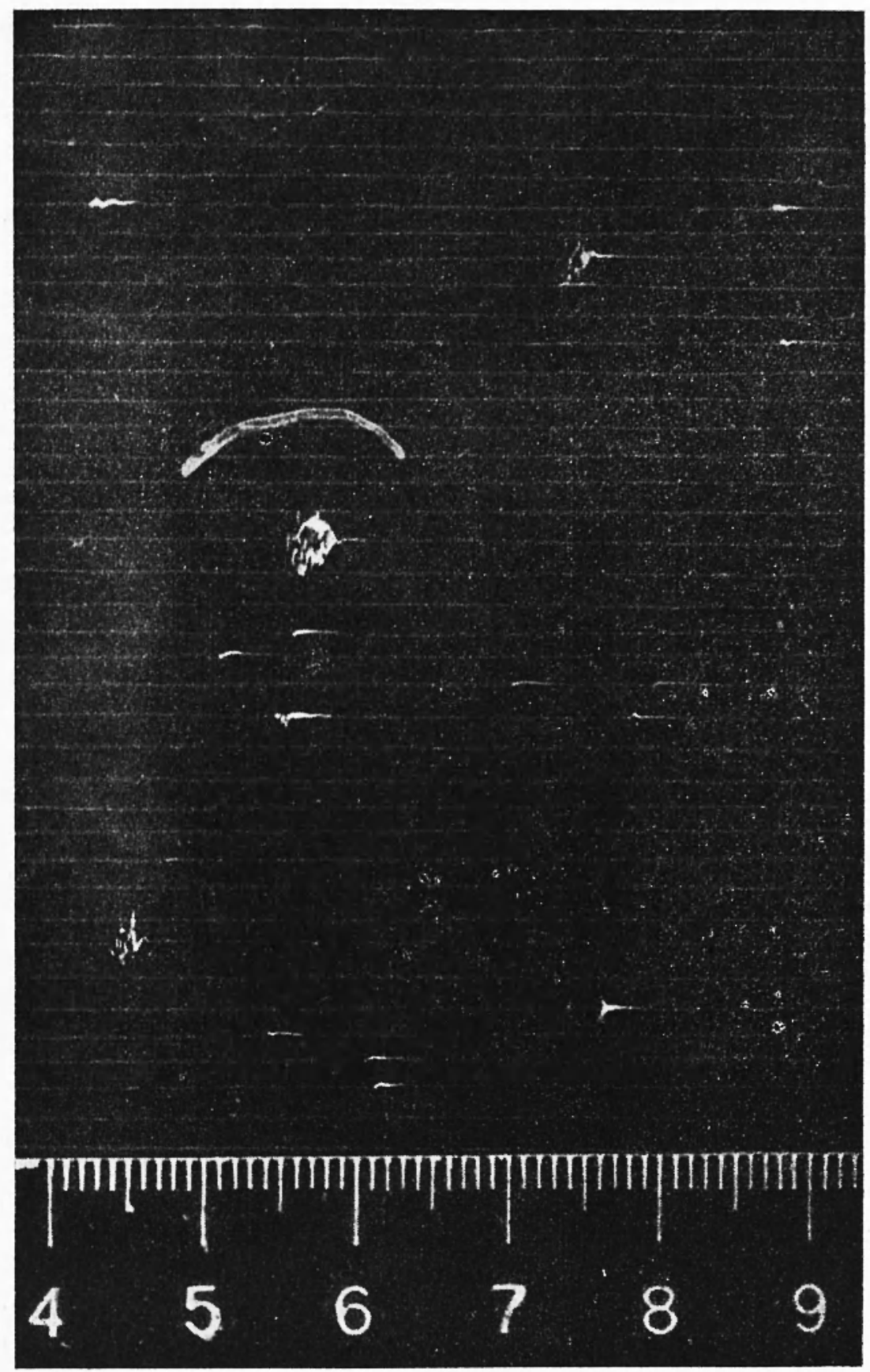

Fig. 8 - Scossette trasmesse da conci prossimi alla stazione sismica (comp. E.W : 2.3.X] 1951). 
sette, determinate da lievissimi scotimenti nel sistema roccioso, che tendeva verso nuove posizioni d'equilibrio.

In molti casi, fu possibile determinare la posizione-origine di queste scossette: la quasi totalità originava dalla parte del bacino ove l'acqua raggiungeva le massime profondità (dell'ordine di $100 \mathrm{~m}$ ).

Le figure $4,5,6,7$ danno esempi di registrazioni di scossette provenienti dal bacino idrico.

Anche durante i primi svasi, si eblue un'accentuata registrazione di piccole scossette.

Molte di queste originano alla base dei conci ed hanno caratteristiche speciali, che le distinguono per la maggiore frequenza e la persistenza delle vibrazioni (fiqure $8,9,9$ bis).

Si sono verificati periodi di notevole attività microsismica, del tutto indipendenti dall'alternarsi di invasi e svasi.

Di essi, diremo più avanti.

Fu possibile determinare l'approssimativa energia sviluppata da singole scossettine, suddivise in quattro tipi.

Consideriamo un'onda armonica semplice di ampiezza $x$ e periodo $T$; l'energia attraversante l'unità d'area di un pennello d'onda, per unità di tempo, è

$$
U=\frac{\varrho}{2}\left(\frac{2 \pi}{T}\right)^{2} v x^{2},
$$

dove $v$ è la velocità di propagazione e $\varrho$ la densità della roccia.

Se si ritiene che l'energia si propaghi dalla sorgente uniformemente in tulte le direzioni, possiamo moltiplicare $U$ per $2 \pi \Delta^{2}$, dove $\checkmark$ è la distanza focale: avremo cosi l'energia totale attraversante una emisfera di raggio $J$, per unità di tempo. Moltiplicando quindi per la durata $t$ in secondi del treno d'onda alla distanza $\Delta$, l'approssimata energia della scossa sarà espressa da

$$
F_{\mathrm{e}}=4 \pi^{3} \varrho v t\left(\frac{x}{T}\right)_{d}^{2} \Delta^{2} \quad \text { c.re.s. }
$$

Per determinare il valore di $\Delta$, hasta conoscere l'intervallo $s-p$ fra i tempi di registrazione delle onde trasversali (s) e longitudinali ( $p$ ). In ricerche precedenti, furono determinate le velocità di propagazione delle onde longitudinali e trasversali per il sistema roccioso, costituente la base del bacino idroelettrico. 


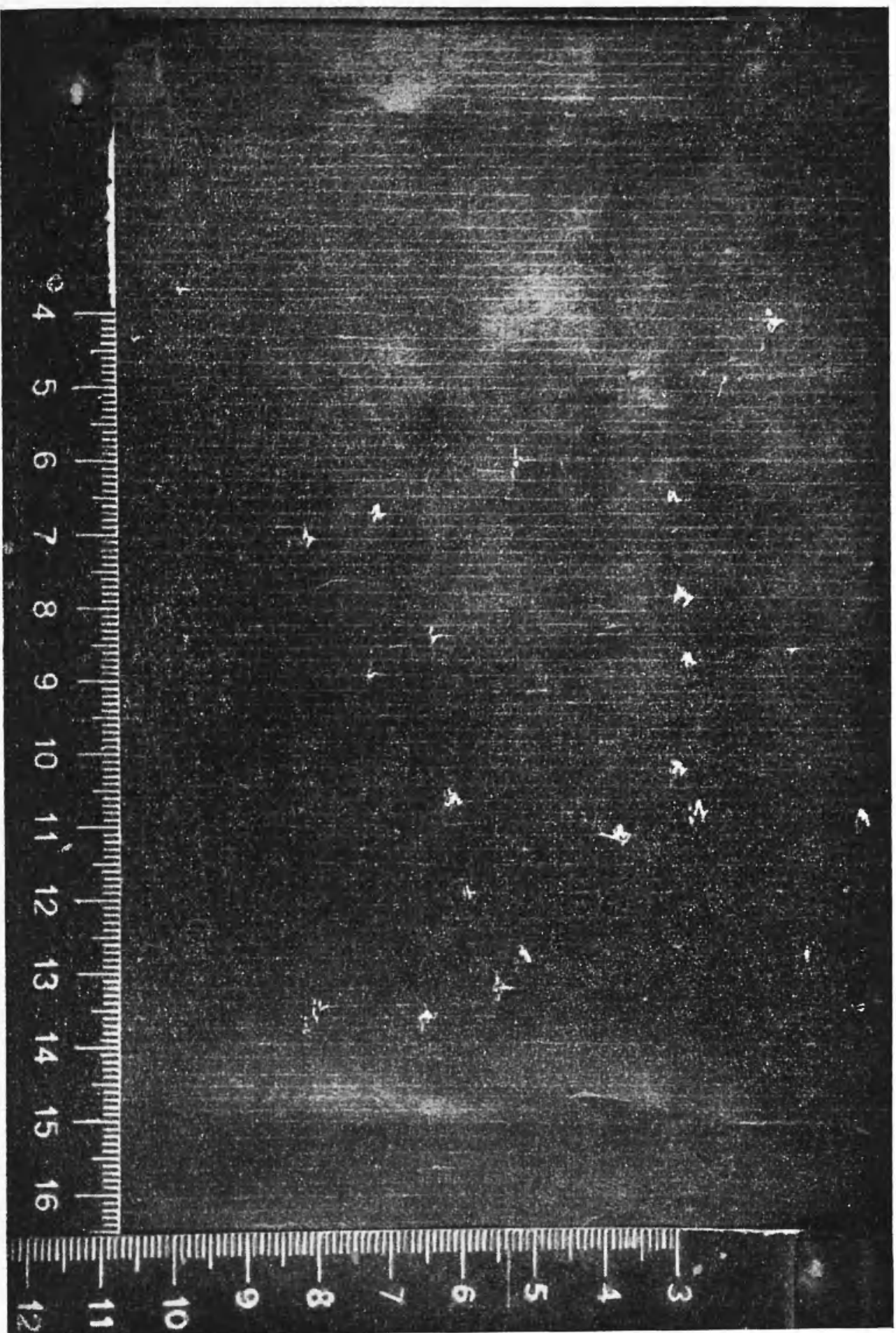

Fig. 9 - Attività sismica intensissima (comp. E-W: 9-10-X 1951). 


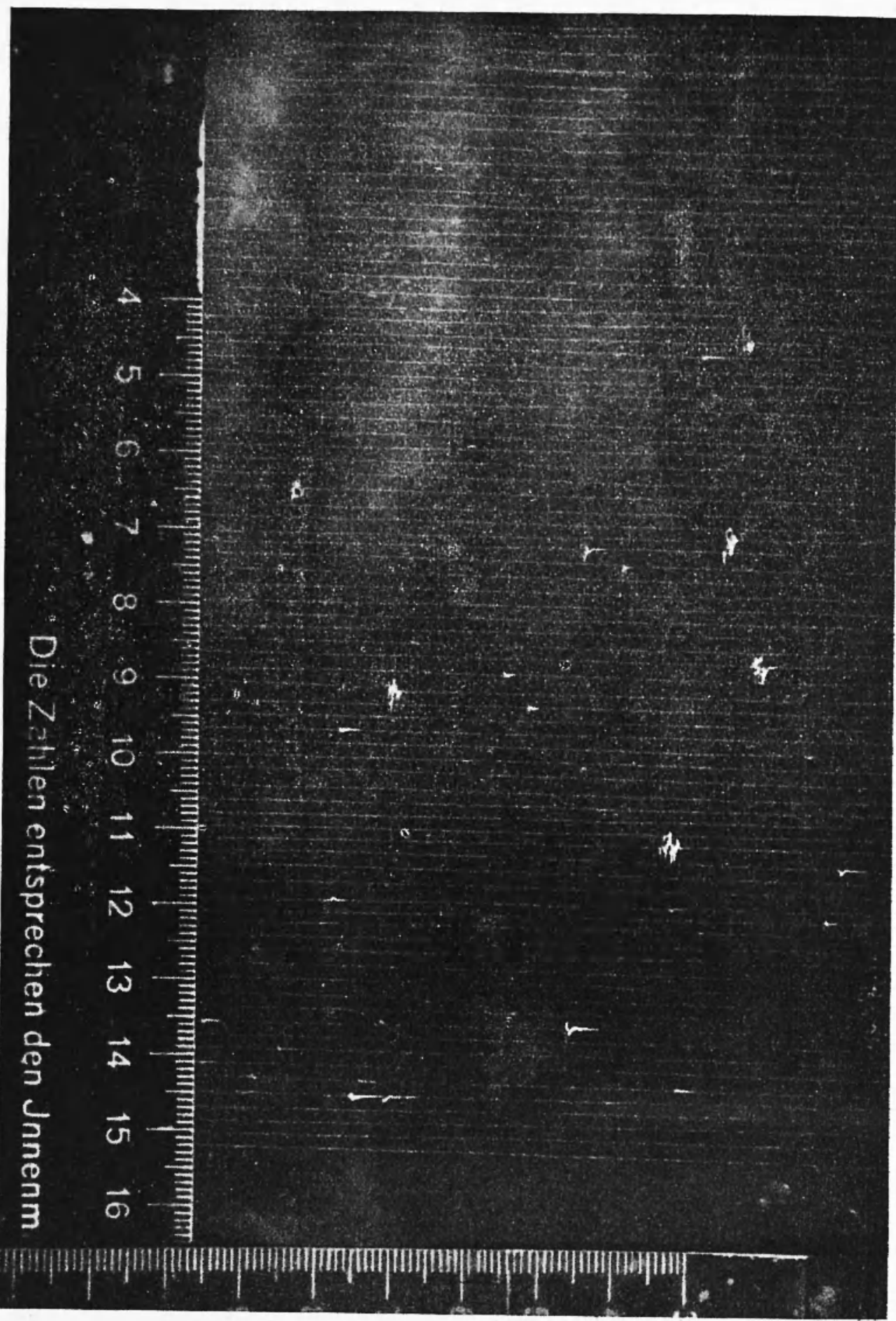

Fig. 9 bis - Attività intensa (scosse di II e III del 12-13-XI 1951, comp. E-W). 


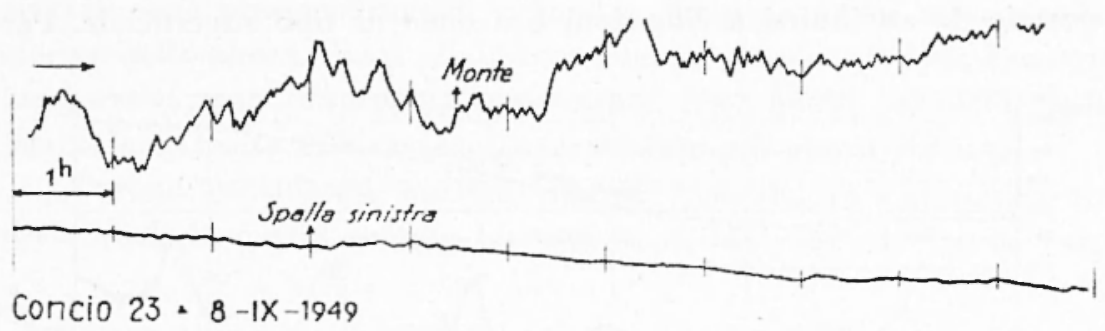

Fig. 10

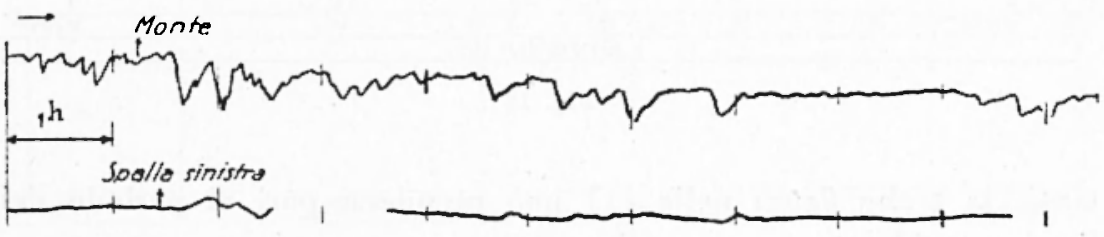

Concio $23 \cdot 29-1-1950$

Fig. 11

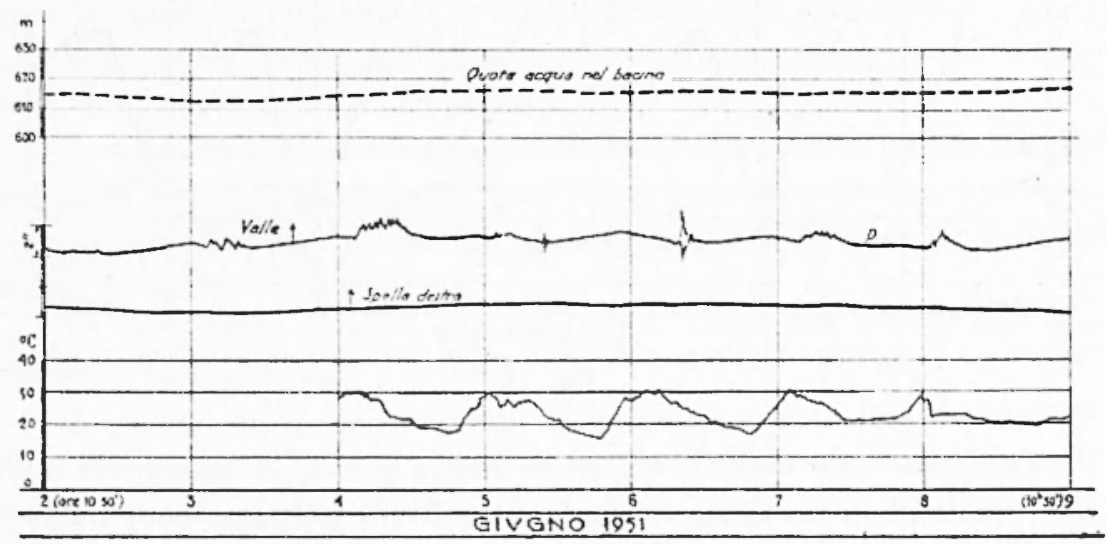

Fig. 12 
Osserviamo che le $p$ e le $s$ si presentano generalmente come consistenti in un'onda completa; le altre oscillazioni che seguono le $s$ essendo da attrilunirsi a riflessioni e a onde di tipo superficiale. Per-

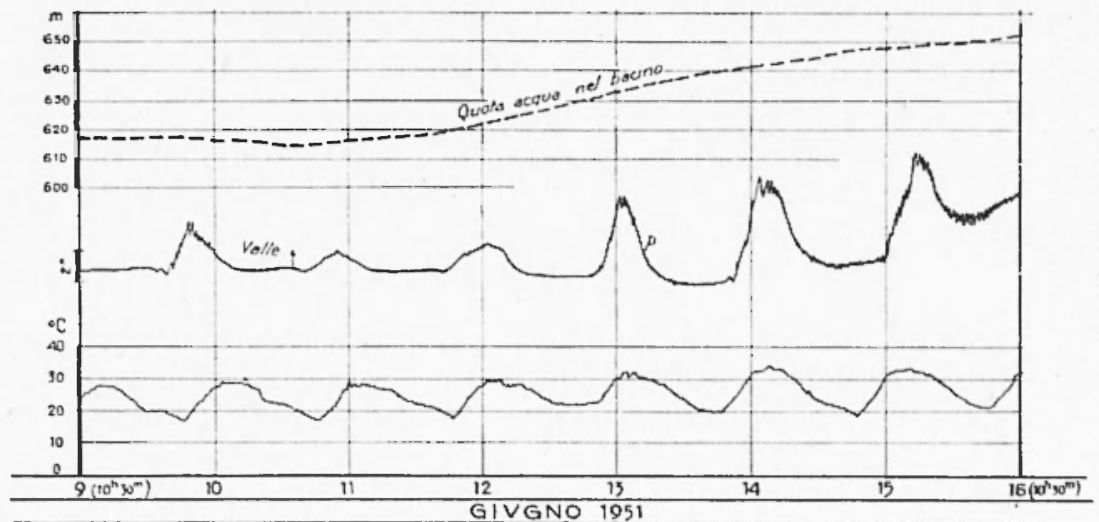

Fig. 13

tanto, la $t$ che figura nella [1] può prendersi pari al periodo dell'onda considerata.

Il risultato ottenuto applicando la [1] ad una singola componente,

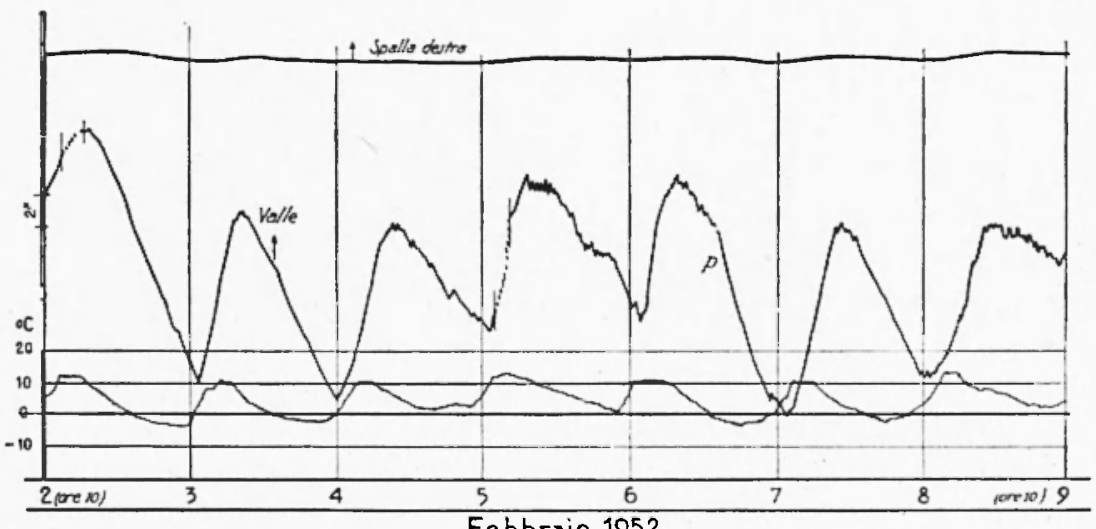

Fig. 14

limitatamente alle onde $s$, andreble diviso per 4 , in quanto le onde $s H$ (oscillanti in un piano normale a quello di propagazione) vengono amplificate del doppio dalla superficie libera, mentre un'amplificazione leggermente minore presentano le onde $s V$ (oscillanti nel piano 
di propagazione). Però il risultato stesso andrebbe moltiplicato per 4, poiché le energie irradiate dalle onde longitudinali e da quelle trasversali sono pressoché uguali e, inoltre, l'energia media nella corona sferica della scossa è pari alla media energia cinetica. Perciò, l'energia complessiva, per una singola componente, resta quella calcolata applicando la [1] alla $s$ osservata (generalmente più ampia della $p$ ).

Furono considerati quattro tipi di scossette, in corrispondenza delle quali la media energia liberata fu di $10^{10}, 10^{11}, 10^{12}$ e $10^{13}$ erg

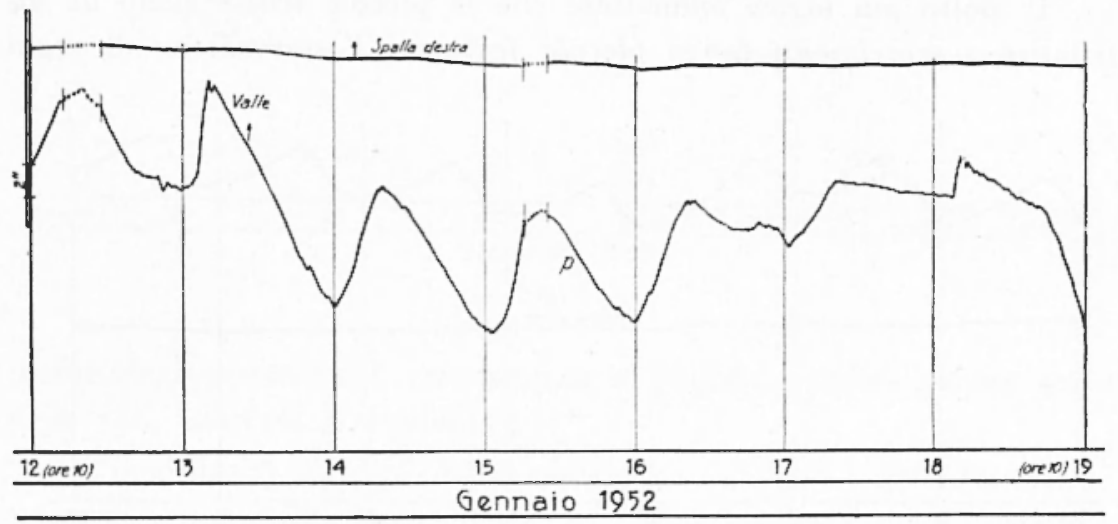

Fig. 15

rispettivamente. Numerosissime furono le scossettine valutate di energia dell'ordine di 10": erg.

Richiameremo più avanti l'ordine di grandezza dell'energía liberata in qualche periodo di attività microsismica anormale.

Qui vorrei richiamare un'altra caratteristica delle scossette, proprie del bacino sotto osservazione.

È noto che dal senso dei movimenti iniziali determinati da una scossa in un certo numero di osservatori, opportunamente distribuiti intorno all'epicentro, è possibile risalire alla natura fisica della causa a cui la scossa è dovuta.

Di che natura sono le scossette che si osservano nel bacino idroelettrico in questione?

A prima vista, una risposta sembrerebbe impossibile: i dati di una sola stazione sismica sono infatti insufficienti a chiarire il fenomeno nei suoi diversi aspetti.

Nel nostro caso però, una risposta sufficientemente attendibile può essere data. Va messo in evidenza che queste scossette si verificano 
sovente in brevissimo intervallo di tempo. Il fatto che, in detto intervallo, si siano verificate, nella stessa stazione d'osservazione, scosse caratterizzate da compressioni o da dilatazioni può senz'altro farci escludere che i movimenti, a cui le scosse stesse vanno attribuite, siano state di sollevamento o di abbassamento. Non si può pensare infatti che movimenti verticali di segno contrario possano verificarsi a distanza di poche ore --a addirittura di minuti - uno dall'altro, come nel caso in esame.

È molto più logico ammettere che le piccole scosse siano da attribuire a scorrimenti lungo piccole fratture: l'osservazione di segni

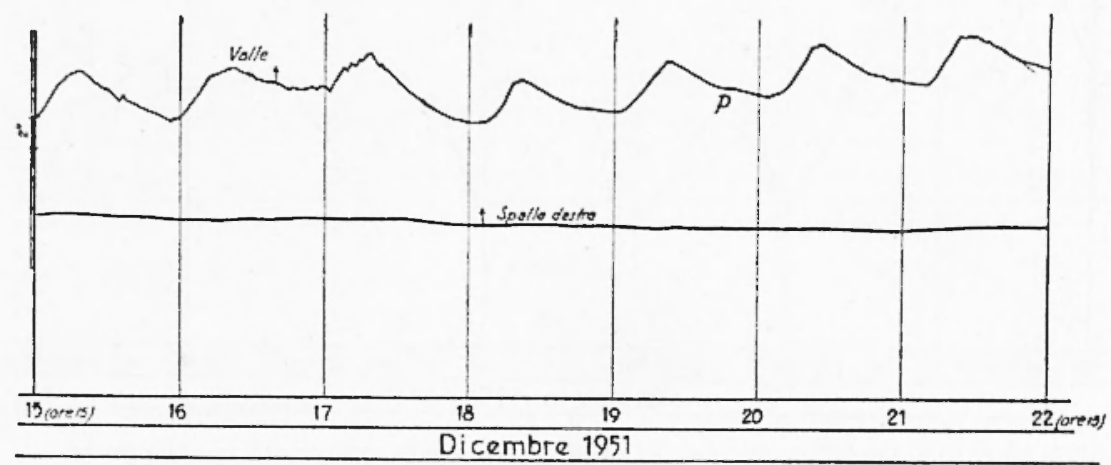

Fig. 16

iniziali contrari per le onde longitudinali, sta a significare che il piano di frattura muta da una scossa all'altra o da una serie all'altra di piccole scosse. Questa interpretazione trova pure sostegno nel fatto che i centri di scotimento sono molteplici, sparsi un po' dovunque in tutta l'area a ridosso della diga.

6. - Ho esposto altrove ( $\left.{ }^{3}\right)$ la teoria del fotoclinografo, parecchi esemplari del quale sono attualmente in funzione presso alcune dighe. Mi limito a riportare la formula che ne esprime l'ingrandimento.

Se o rappresenta la deviazione dell'immagine alla distanza di un metro, si ha

$$
\delta=75 \frac{\stackrel{\sigma}{\sigma}}{\pi^{2} l} \psi^{\prime} T^{2},
$$

dove $g$ è l'accelerazione di gravità, $l$ la lunghezza ridotta del pendolo 
bifilare, $\psi$ l'angolo di variazione della verticale apparente e $T$ il periodo proprio del pendolo.

I fili di sospensione sono di costantana. Ecco le caratteristiche

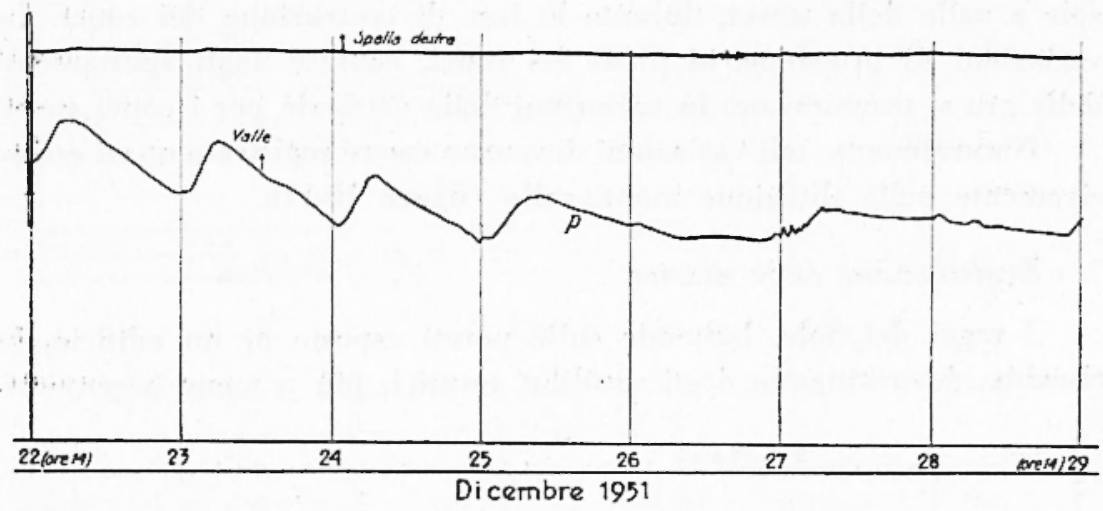

Fig. 17

medie degli apparecchi, attualmente in funzione presso alcune dighe e in vari Osservatori italiani:

$\begin{array}{ll}\text { modulo di rigidità della costantana } & =6,1 \cdot 10^{11} \mathrm{dine} / \mathrm{cm}^{2} \\ \text { lunghezza fili sospensione } & =\mathrm{cm} 9 \\ \text { massa } & =\mathrm{gr} 16,5 \\ l \quad \text { (lunghezza ridotta pendolo) } & =\mathrm{cm} 7 \\ \text { diametro fili sospensione } & =75 \text { micron. }\end{array}$

Un indice delle possibilità dei fotoclinografi del tipo bifilare nella registrazione delle variazioni della verticale apparente è dato dalla fig. 10. In essa si ha un esempio di registrazione delle perturbazioni

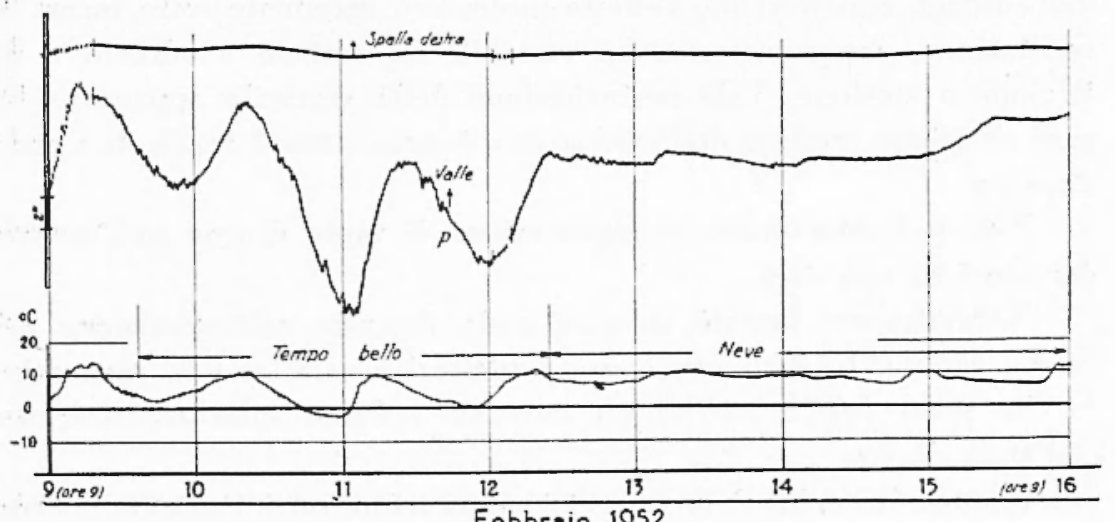

Fig. 18 
registrate nella postazione di un concio centrale di una grande diga in costruzione, e determinate dall'andirivieni delle grosse gru sopra le apposite rotaie, che correvano parallelamente alla diga nel piazzale a valle della stessa, durante la fase di costruzione dei conci. Le variazioni di pressione, ai piedi dei conci, causate dagli spostamenti delle gru si tramutavano in variazioni della verticale per $i$ conci stessi.

Naturalmente, tali variazioni dovevano essere registrate quasi esclusivamente nella direzione monte-valle (figure 10-11).

\section{7. - Registrazione onda diurna.}

I raggi del Sole, battendo sulle pareti esposte di un edificio, le riscalda, determinando degli squilibri termici, più o meno accentuati,

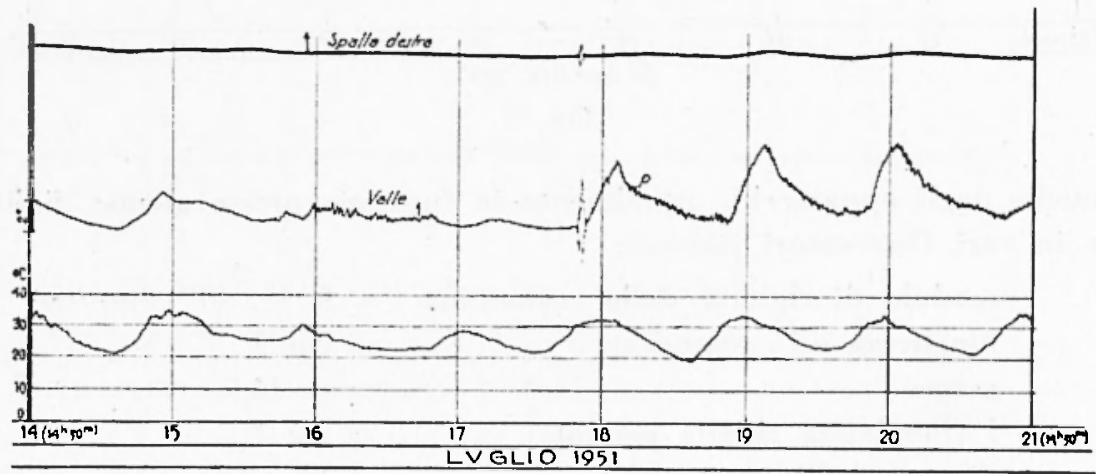

Fig. 19

fra pareti esposte e pareti riparate. L'azione termica è accompagnata da un'azione meccanica sull'edificio; un clinografo posto nell'interno dell'edificio, registrerebbe l'effetto meccanico accennato sotto forma di oscillazione, con caratteristiche variabili da edificio a edificio e da stazione a stazione. Tale perturbazione della verticale apparente, legata all'azione termica dell'insolazione, è nota sotto il nome di " onda diurna ").

Non potevano mancare registrazioni di onde diurne nell'interno dei conci di una diga.

Naturalmente l'entità di quest'onda dipende dall'esposizione del concio al sole. In certi conci essa è molto limitata, se non mancante.

Lo stato dell'invaso ha un notevole influsso sulla registrazione dell'onda diurna.

Quando il bacino è in fase di riempimento, od è riempito, l'onda diurna è sempre netta - in giornate di sole, s'intende. 


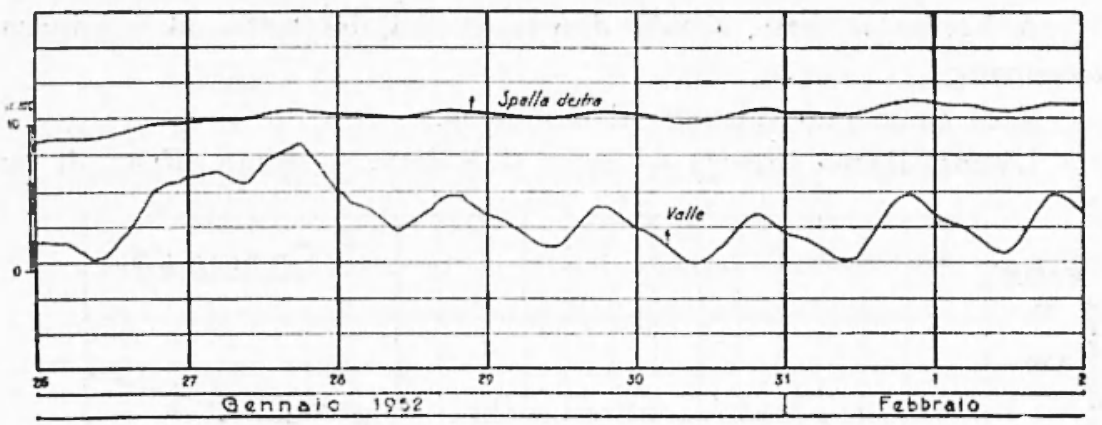

Fig. 20

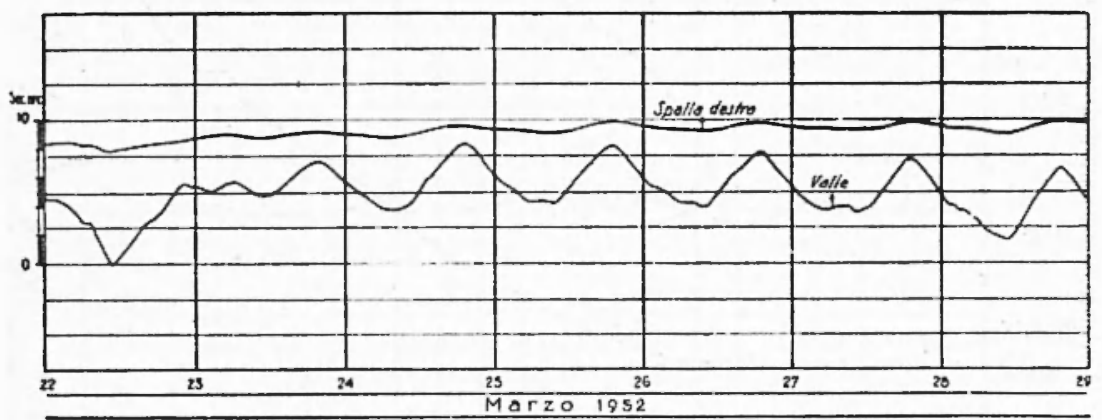

Fig. 21

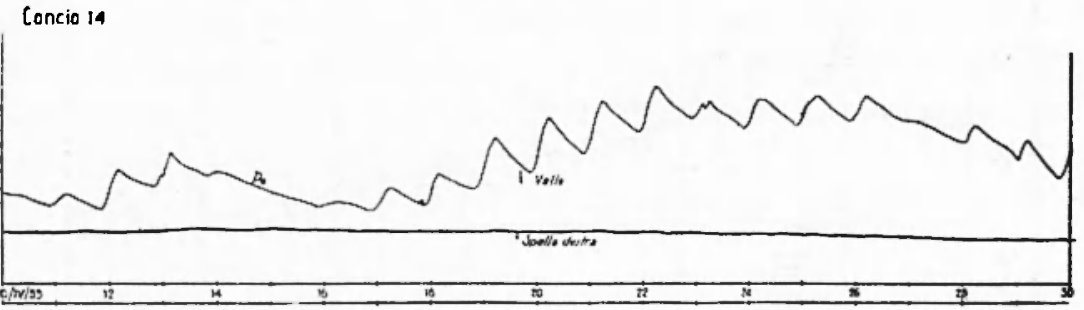

Fig. 21 bis - (Riduzione $3 / 10$; nell'originale $1 "=3 \mathrm{~mm}$ ).

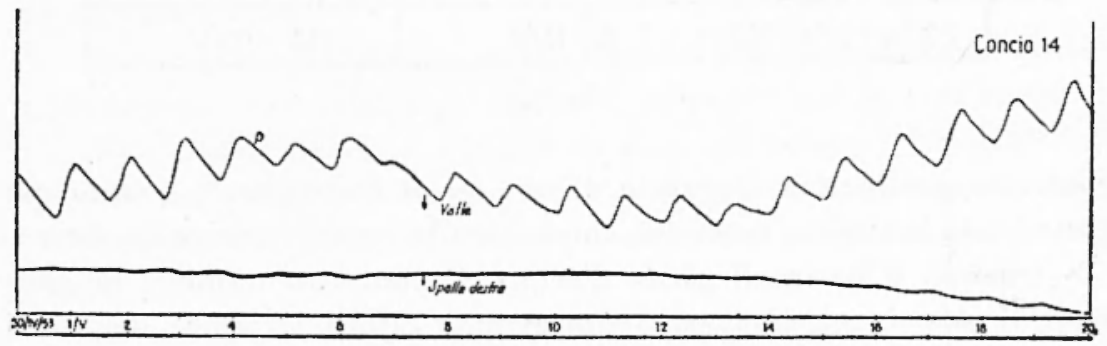

Fig. 21 ter - (Riduzione $3 / 10$; nell'originale $1^{n}=3 \mathrm{~mm}$ ). 
A bacino asciutto, l'onda diurna manca del tutto od è appena accennata.

Ecco come può spiegarsi il fenomeno.

L'onda diurna insorge - come si è detto - come effetto di un

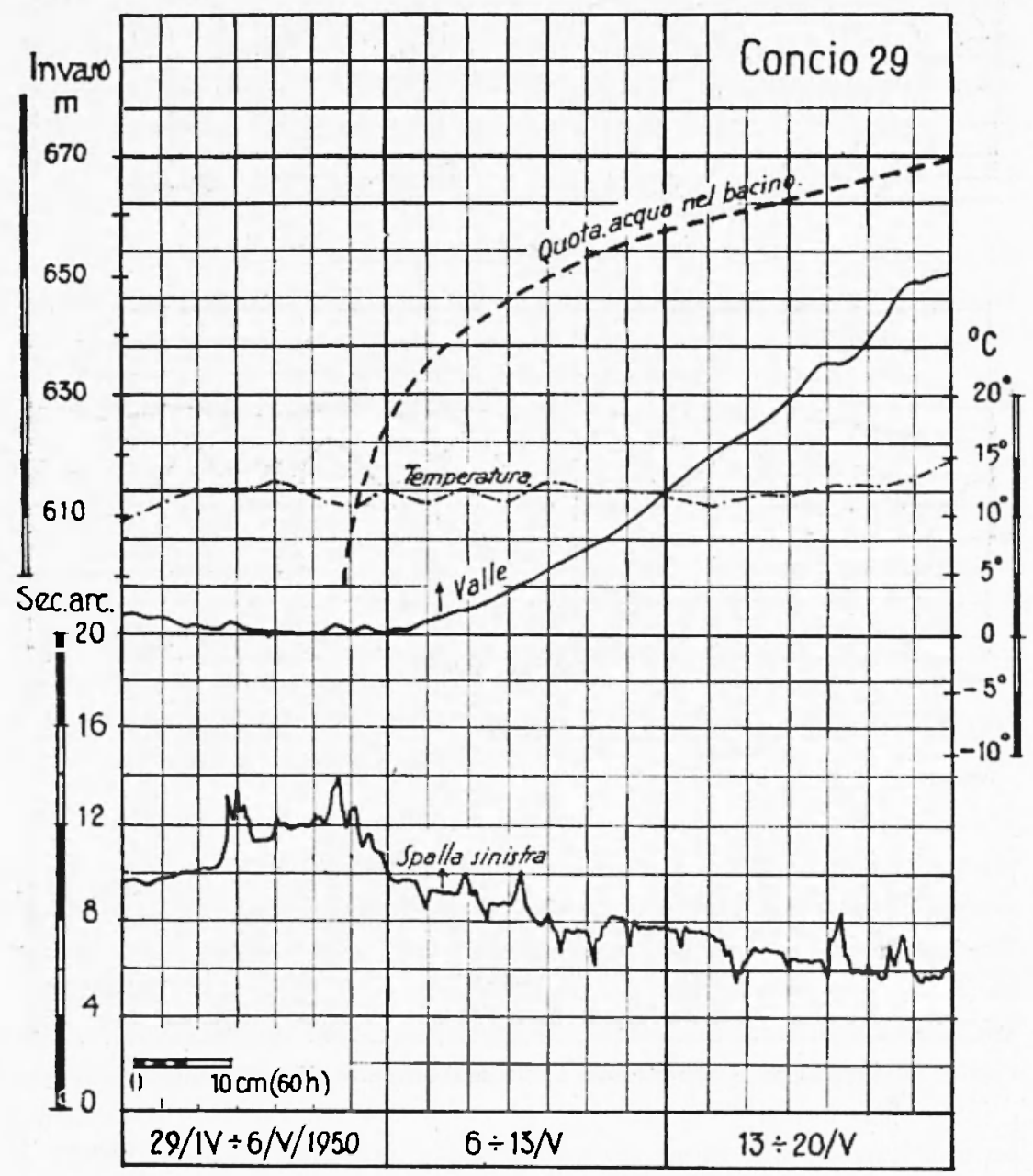

Fig. 22

contrasto termico fra superficie di una stessa costruzione; quanto più forte è tale contrasto, tanto più ampia sarà la conseguente onda diurna.

Quando il bacino è pieno d'acqua, il contrasto termico, in giornate di sole, è massimo: a monte avremo infatti le pareti dei conci ad una temperatura media da $4^{\circ}$ a $10^{\circ}$, a valle, le pareti dei conci 
possono raggiungere, d'estate, temperature superiori ai $40^{\circ}$. Donde le condizioni per ampie onde diurne.

Se il bacino è asciutı, è chiaro che tale contrasto viene di molto attenuato e - in certe condizioni - addirittura annullato: da qui la registrazione di piccole onde diurne o la mancanza di esse.

Interessanti, a questo riguardo, le registrazioni ottenute durante l'ultima fase dello svaso in un grande bacino (1951): si noti (figure 12.13) la graduale ripresa dell'onda diurna a mano a mano che l'acqua sale nel bacino.

C'è tutta una varietà di onde diurne: onde diurne caratteristiche di una determinata stagione, le quali, a loro volta, evolvono di mese in mese: onde diurne pressoché sinusoidali, altre molto deformate; simmetriche o asimmetriche rispetto alla linea di quiete.

Quando lo scarto termico diurno è molto accentuato, avremo ampie onde diurne (es. 2.9 Febluraio 1952, fig. 14). Se l'inversione termica e lorusca, avremo in corrispondenza estremi acuminati (es. 23-27 Febbraio 1952; 2-5 Feblbraio 1952, firr. 14). Se l'inversione termica ̀̀ graduale, graduale $\grave{e}$ pure il cambiamento di curvatura del corrispondente massimo per l'onda diurna (es. 14-17 Gennaio 1952, fig. 15).

Per piccoli scarti termici diurni, avremo onde diurne poco ampie. Anche qui la forma dell'onda è strettamente legata all'andamento termico diurno. Caratteristica la settimana 15-22 Dicembre 1951, con massimi acuti per brusco riscaldamento ed inversione termica e minimi a grande curvatura per lenta azione di raffreddamento (fig. 16). Dal 22 al 26 dicembre 1952 si hanno esempi di giornate con brevi, rapidi riscaldamenti e graduale, lungo raffreddamento (fig. 17). Altri esempi sono forniti dalle figure 18 e 19.

Le figure 20 e 21 si riferiscono ad una diga più piccola, con diversa esposizione solare.

Nelle figr. 21 bis e 21 ter, marcate onde diurne sono sovrapposte ad ampic oscillazioni a lungo periodo (di 12-14 giorni), sulla componente valle-monte.

Particolarmente efficace riesce l'uso del fotoclinografo nel rivelare il comportamento della diga durante i periodi d'invaso e di svaso.

Tale comportamento, a parità di altre condizioni, è funzione dello spessore della diga e della resistenza (esprimiljile mediante il modulo di elasticita del sistema roccioso in cui sono ancorati i conci della digal.

La figr. 22 dà l'andamento della flessione di una grande diga du- 


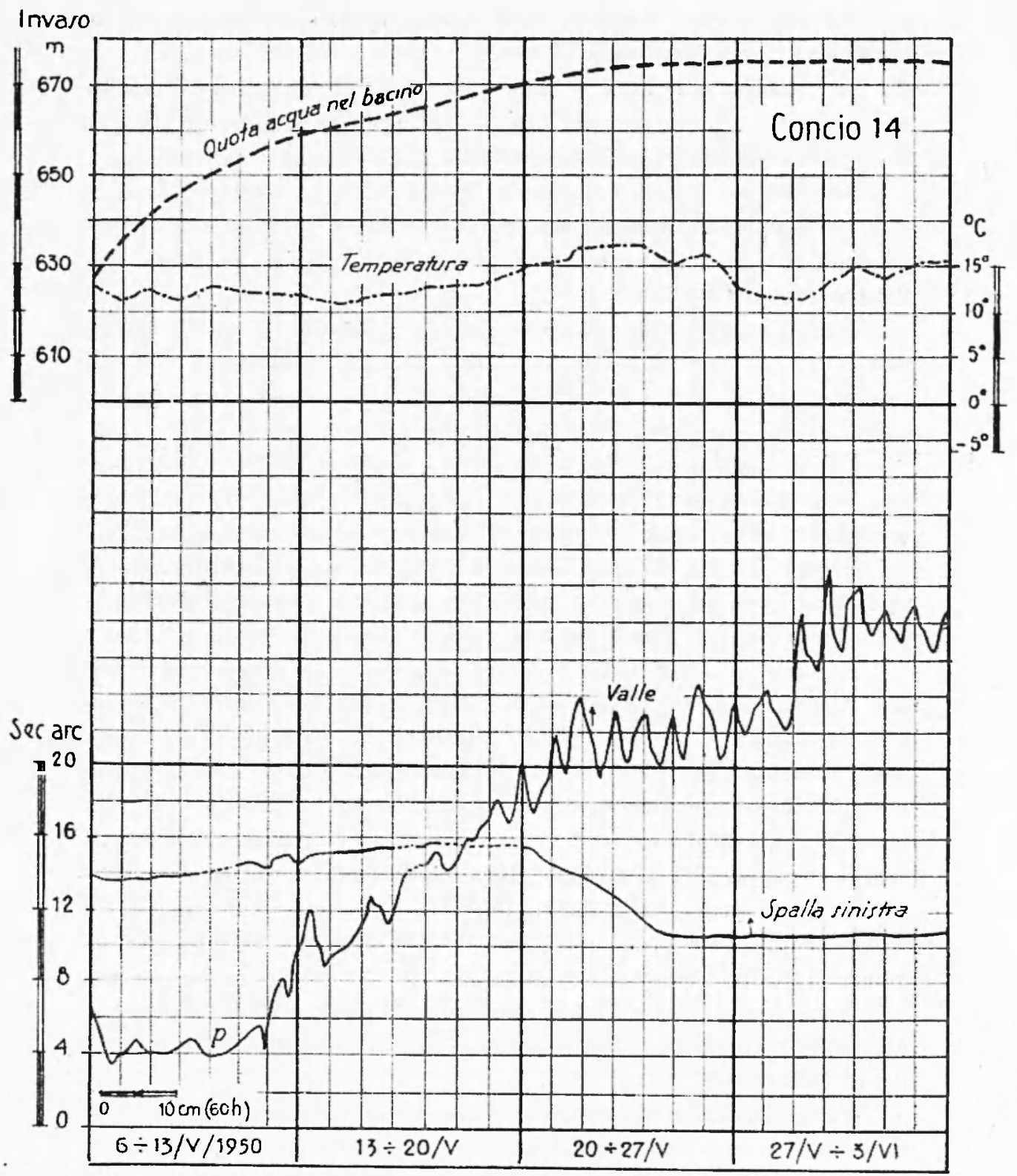

Fig. 23 


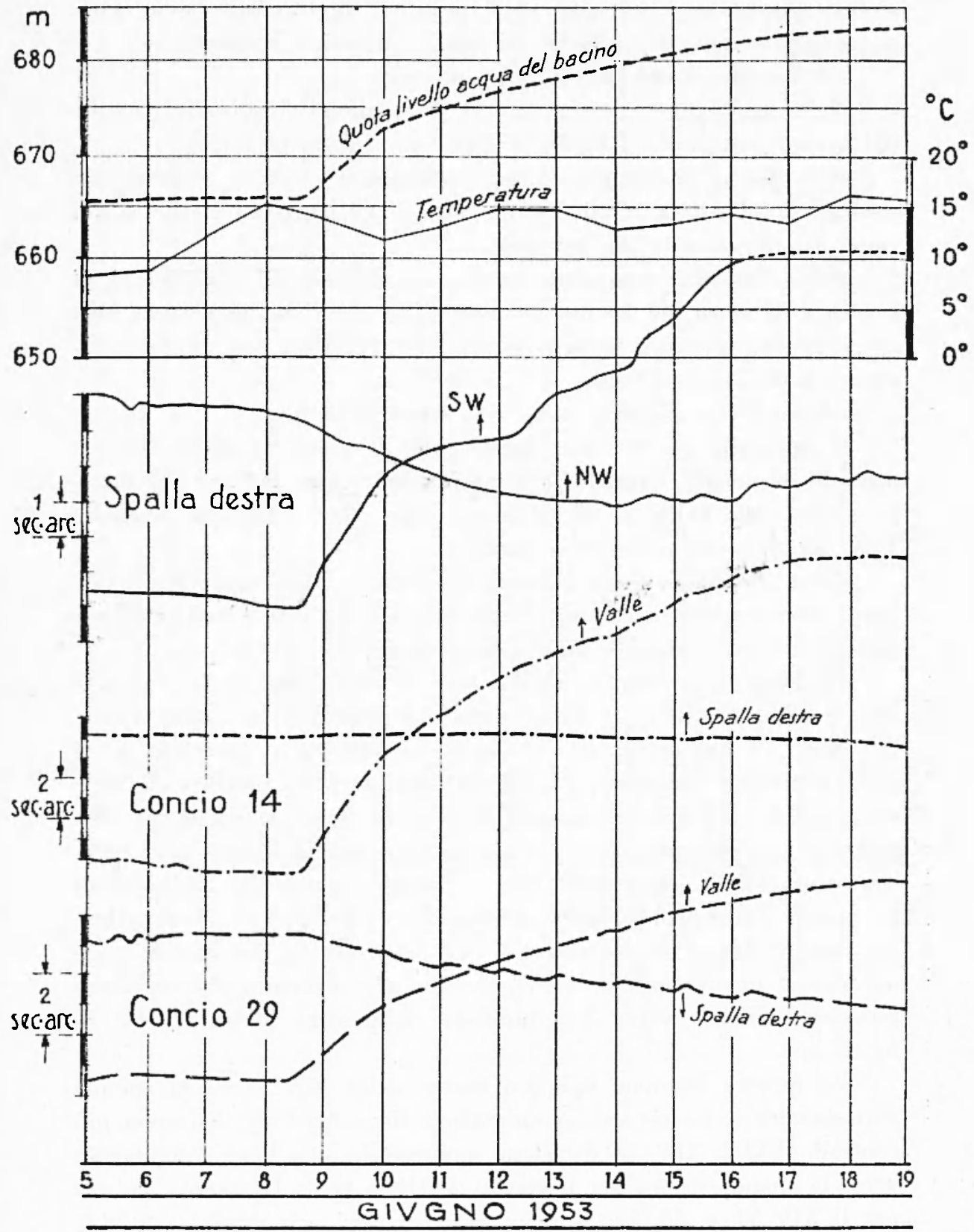

Fig. 23 bis 
rante un invaso in corrispondenza di un concio particolarmente massiccio (spessore $\mathrm{m} 36$ ca, alla base); la fig. 23 riporta la flessione della stessa diga, quale si rivela in un concio di minor spessore.

La flessione è comunque molto piccola.

Nella fig. 23 bis è riportato il caso della spinta verso valle, causata dal brusco aumento del livello d'acqua nel bacino idrico.

Nel caso di dighe più sottili, sostenute da sistemi rocciosi con modulo di elasticità relativamente basso, l'entità della flessione dei conci è naturalmente più sensibile.

Porto l'esempio riprodotto in fig. 24, relativo alle operazioni di invaso e di svaso nel bacino formato dallo sbarramento di una diga relativamente piccola, fondata in un letto roccioso, con modulo elastico relativamente basso.

Anche la fig. 25 si riferisce alla stessa diga.

A proposito di moti non attribuibili a variazioni di invaso o a brusche variazioni termiche o atmosferiche, citerò il caso dei movımenti accusati dalla spalla destra di una grande diga nell'autunno 1950, un anno dopo la sua costruzione.

Come risulta dai dati relativi all'invaso e alla temperatura dell'aria, non esistevano condizioni esterne, tali da giustificare aumenti di sollecitazioni sopra la diga e sulle spalle che la limitano.

Un brusco movimento in direzione $N E$ circa nella settimana $4-11$ Nov. 1950, è seguito — nella stazione clinografica della spalla destra, in roccia - dall'inizio di un ampio movimento a circa $90^{\circ}$ gradi nella settimana successiva, (11-18. XI), con legrgera modifica di direzione $\left(N 42^{\circ} \Pi\right.$ ) nella settimana dal 18 al 25 Nov.: in questi quindici giorni il movimento angolare è stato cospicuo (fig. 26). Contemporaneamente il lato destro della diga - com'è provato dai clinografi di un concio limitrofo alla spalla destra, il concio XXIX - fletteva leggermente verso il complesso roccioso della spalla destra che stara ritraendosi in direzione $W 33^{\circ} N$ ca. (fig. 27), seguendo una direzione prossima all'andamento longitudinale della diga stessa is $42^{\circ} \mathrm{W}$ fig. 27 bis).

La leggera flessione del lato destro della diga verso la sponda corrispondente, ha consentito un'analoga lieve flessione dei conci piî̀ centrali (XXIII, XIV) in direzione monte-valle, con lieve componente verso la sponda destra per il concio XXIII, e verso la sponda sinistra per il XIV (figg. 28, 29).

E sintomatico che quasi a un anno di distanza, con circa un mese di anticipo, si è ripetuto sul lato destro della diga un brusco feno- 


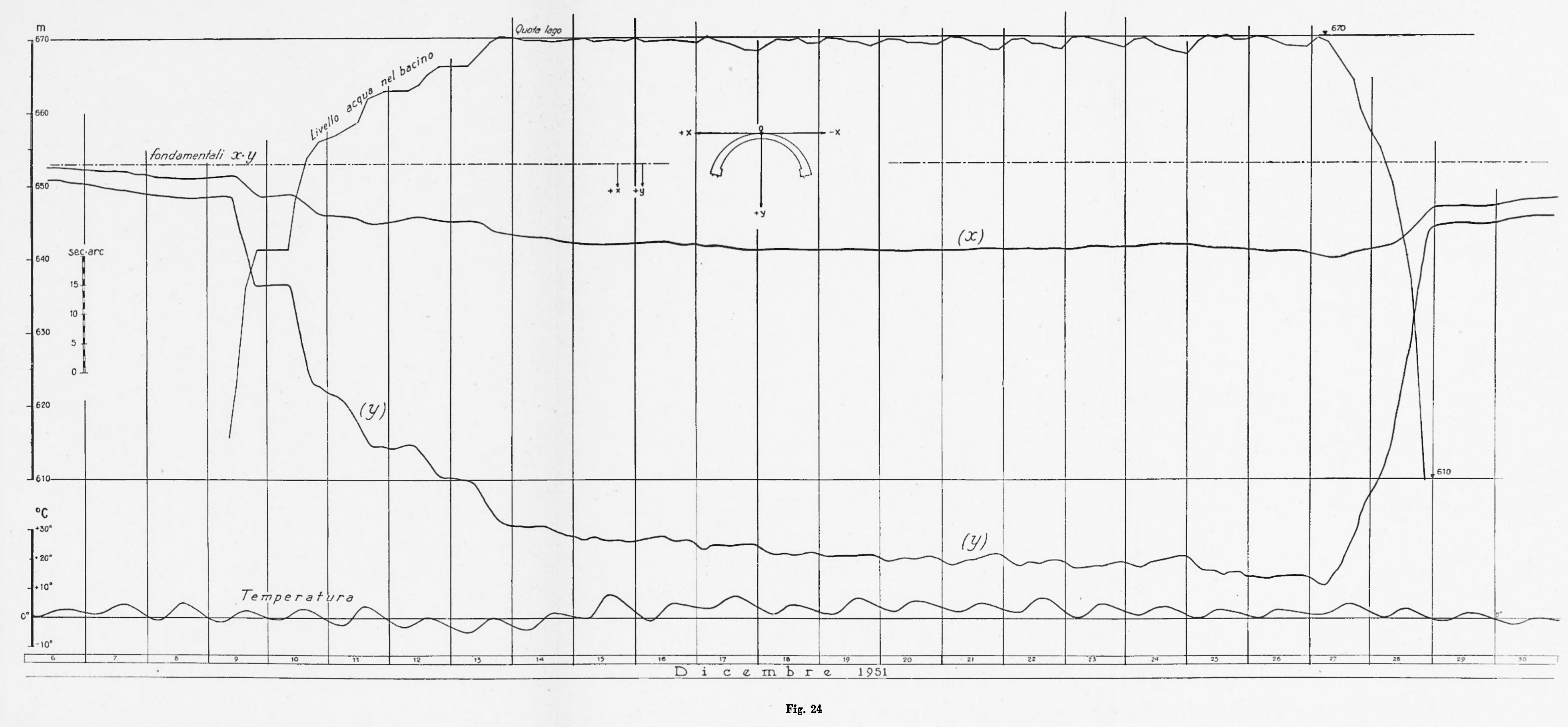


meno di flessione, per il quale non può essere invocata nessuna causale, comunque legata all'invaso, o alla temperatura esterna. L'entità di questo movimento, è stata minore di quella dell'anno precedente. Esso ha dato inizio a un eccezionale periodo sismico, messo in evidenza dalla stazione sismografica funzionante presso la diga, sulla spalla destra (v. pag. 358).

Movimenti di un blocco, limitato ad oriente dalla sponda destra del fiume?

Parecchi indizi lasciano ritenere attendibile questa ipotesi.

8. - Osservazioni clinografiche complessive nel periodo 6 Maggio 195/) . 16 Giugno 1951, tra due svasi consecutivi.

a) Concio XIV (sul centro-sinistro della diga). I due grafici (fig. 29) si riferiscono alle registrazioni clinografiche ottenute alla base del concio XIV, nei periodi dal 6 Maggio al 26 Agosto $1950 \mathrm{e}$ dal 28 Ottobre al 16 Giugno 1951. L'interruzione di circa due mesi è dovuta ai disturbi causati da lavori in corso presso la stazione clinogrrafica.

I diagrammi costituiscono le risultanti delle registrazioni ottenute contemporaneamente dalle due componenti clinografiche: una oscillante normalmente al concio (valle-monte: $N^{\circ} 10^{\circ} \mathrm{E}-\mathrm{S} 10^{\circ} \mathrm{W}$, l'altra in senso longritudinale alla diga $\left(E 10^{\circ} \mathrm{S} \cdot \mathrm{IF}^{\prime} 10^{\circ} \mathrm{N}\right)$.

Nel periodo di invaso si ha una spinta verso valle, con andamento pressoché continuo. Segue poi un periodo di relativa stasi, con piccoli moti contrastanti.

Dal 28 Ottobre 1950 al 3 Febbraio 1951 i movimenti, sempre piccoli, ora in un senso ora in un altro, sono caratteristici di un periodo di stabilità.

Dal 3 Febbraio 1951 i movimenti iniziano una decisa tendenza valle-monte, interrotta da bruschi parziali ritorni in senso contrario.

Da questo momento fino al momento dello svaso completo, il grafico risulta da un insieme di figure, simili a quelle di Lissajous.

Come risulta dal comportamento del concio XXIII e XXIX, la spinta verso valle alla fine dell'Agosto 1950 non doveva essere lontana dal suo massimo.

L'escursione angolare negli ultimi tre mesi che hanno preceduto lo svaso è stata, come si osserva, più sensibile della spinta verso valle conseguente all'invaso. Dobbiamo concluderne che - almeno per quanto riguarda il concio $\mathrm{XIV}$ - nel ritorno alle condizioni di 


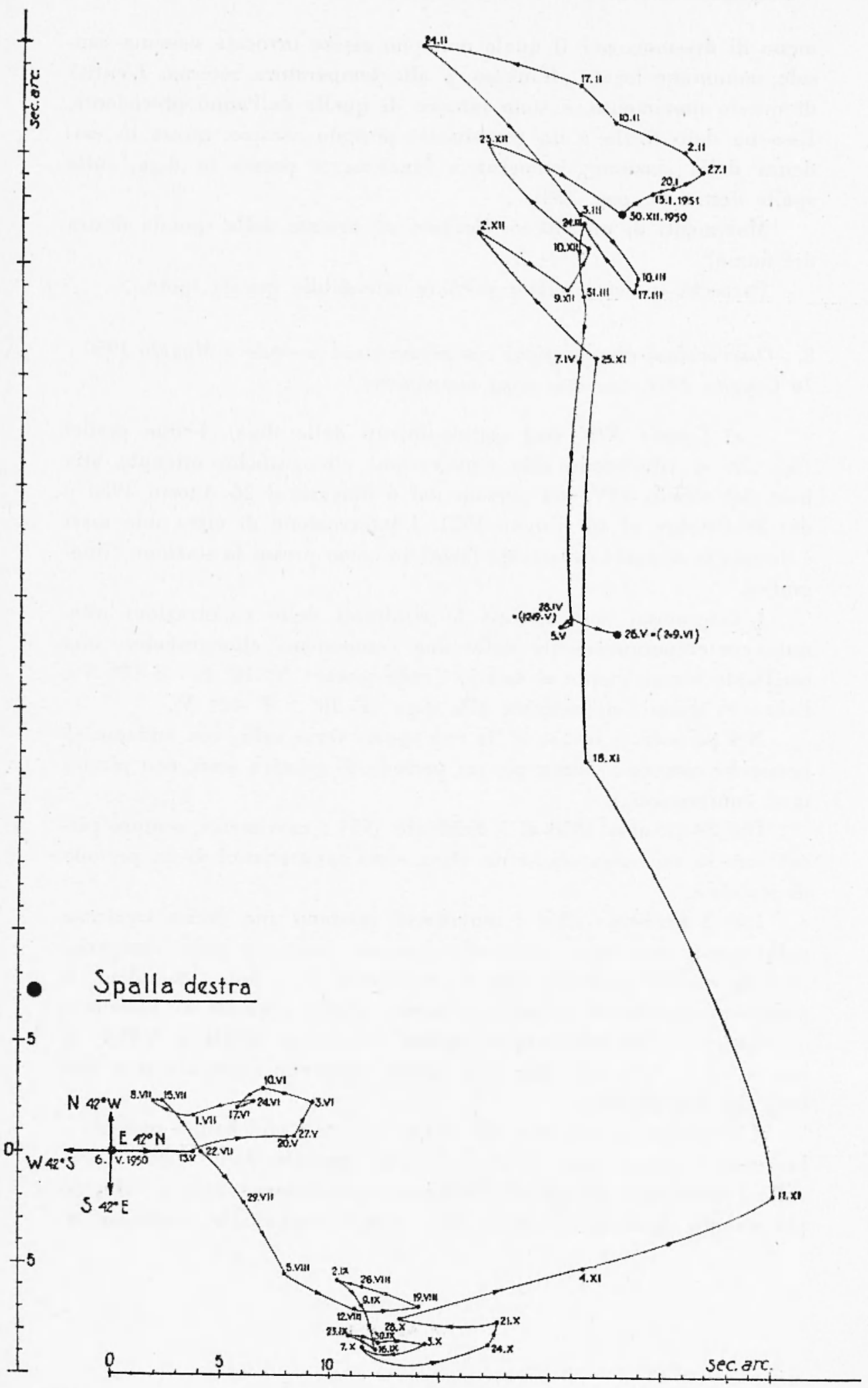

Fig. 26 


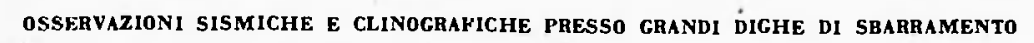
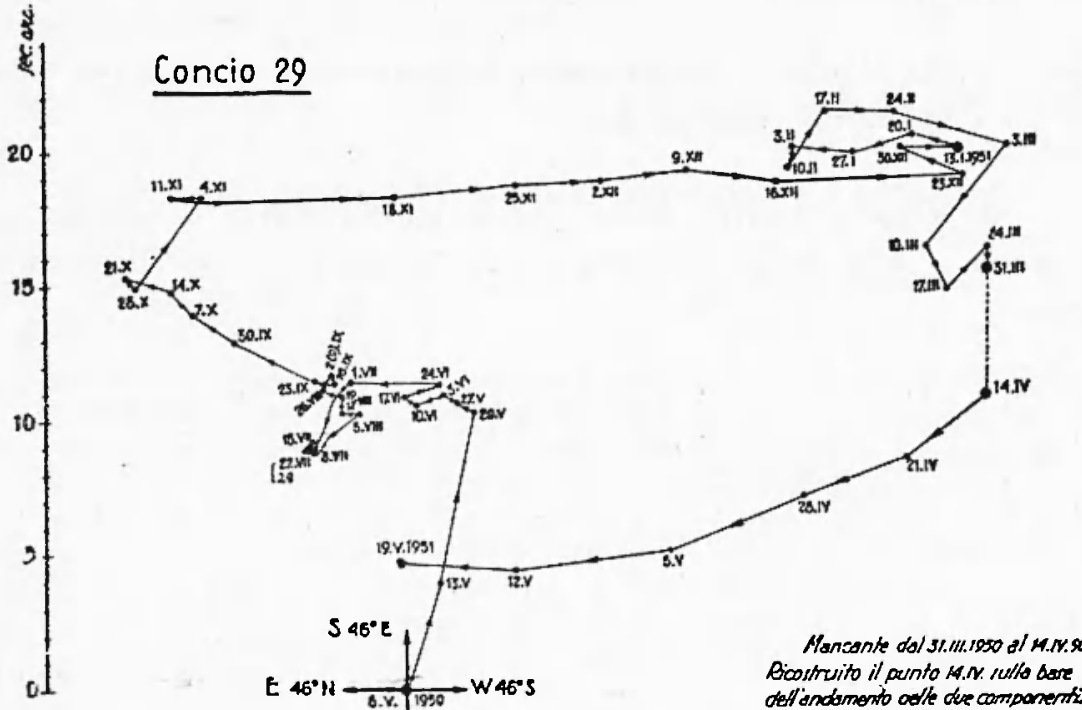
defindinento adk des companemi:

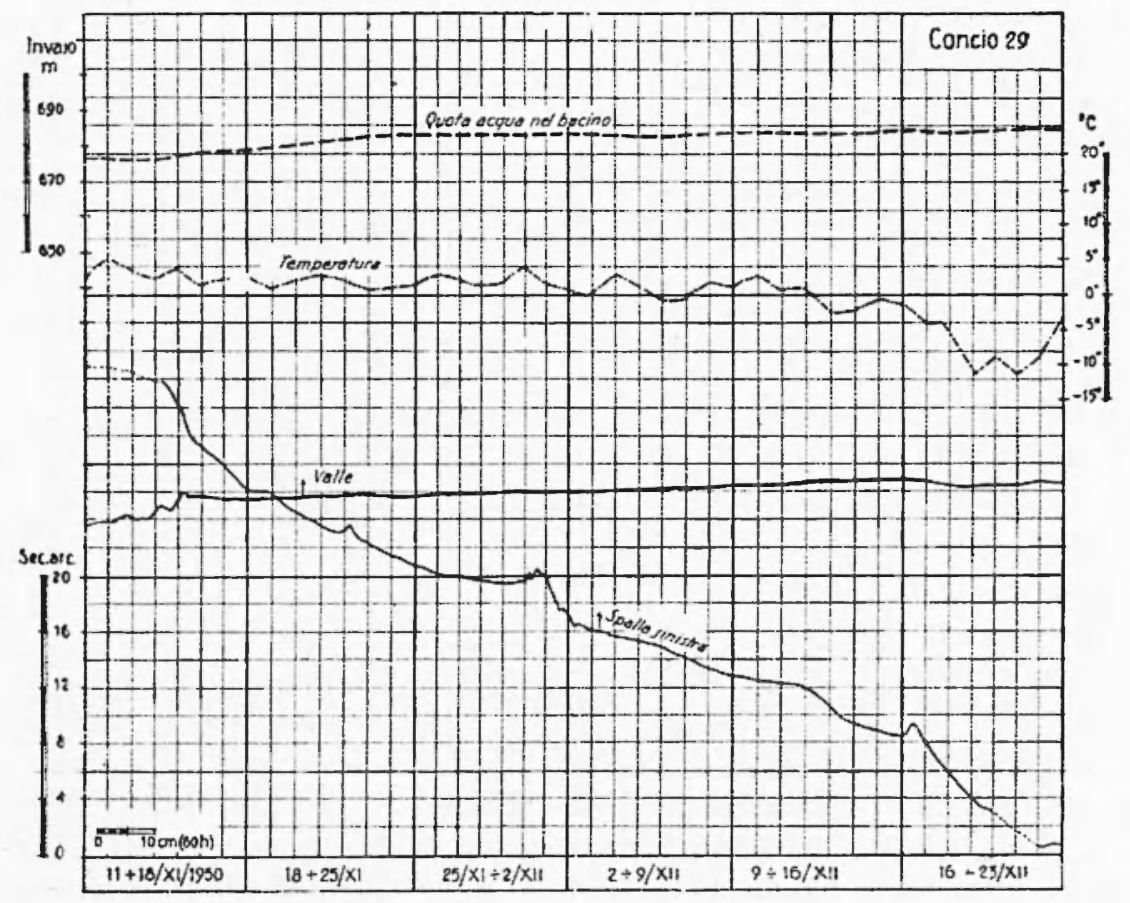

Fig. 27 bis 
spinta nulla, il concio ha sorpassato la posizione originaria per " cadere" leggermente verso il bacino.

b) Concio XXIII. Anche per il concio XXIII il movimento angolare si è avuto prevalentemente in direzione monte-valle e viceversa.

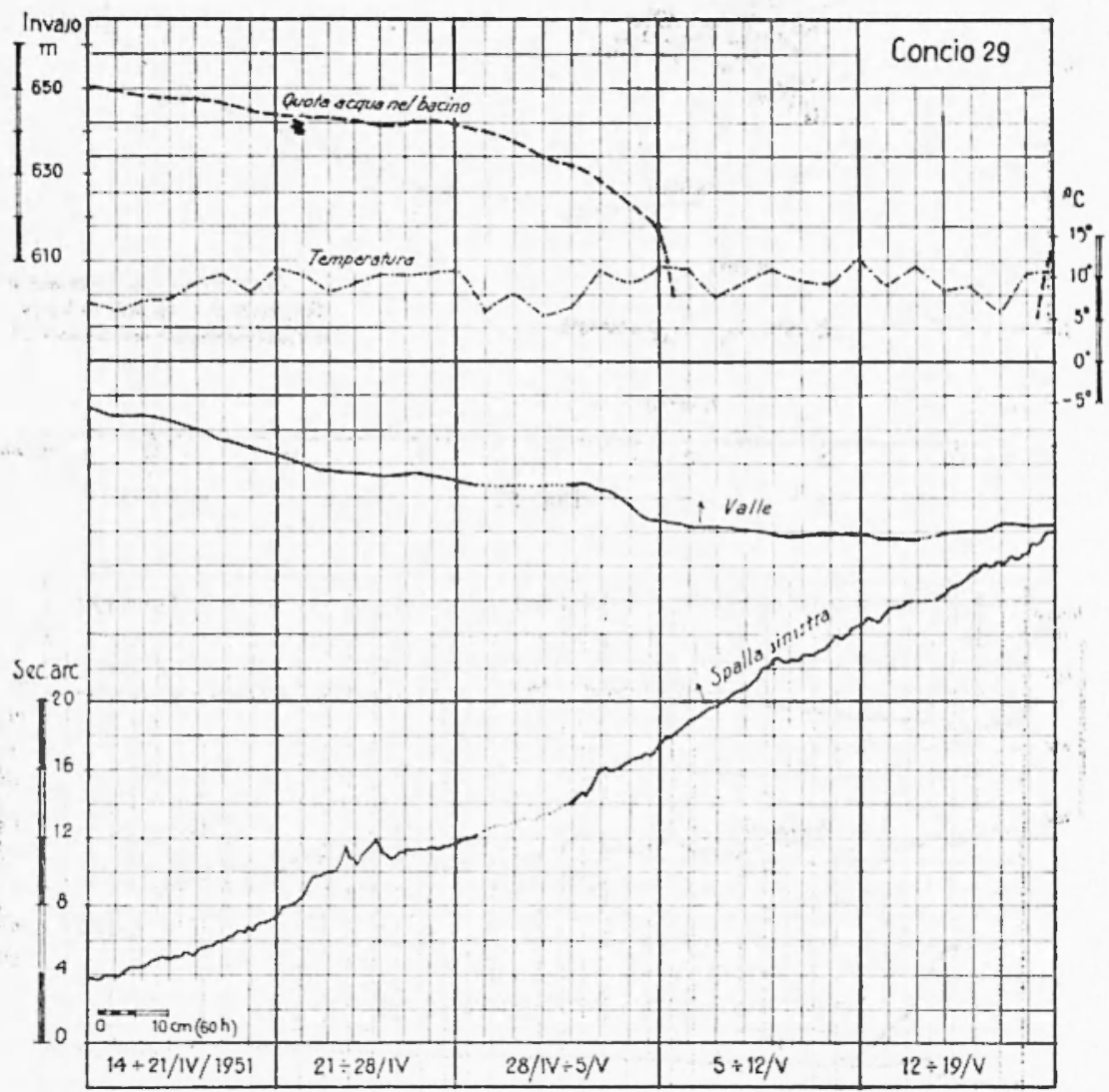

Fig. 28

L'azione dell'invaso si è manifestata lenta e contrastata fino al J6-IX-50 (fig. 29 ).

Da questa data, essa assume carattere deciso ed unidirezionale - salvo qualche manifestazione di segno contrario in Dicembre 1950 e ai primi di Gennaio 1951 - fino al 20 Gennaio 1951. A comin- 
ciare da questo giorno, il moto g'inverte fino al quasi completo svaso del bacino.

In quest'ultima fase, le variazioni angolari sono contrastanti.

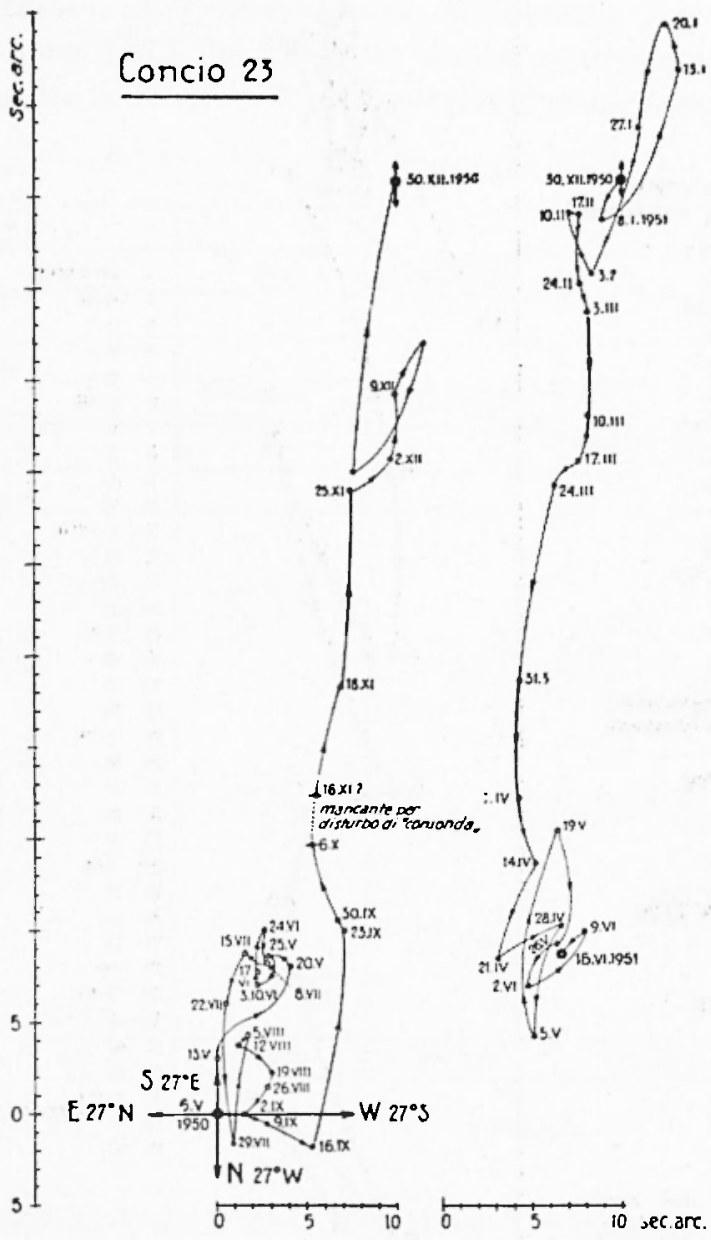

Fig. 29

Il diagramma $i$ stato spezzato in due, per ovviare ad inevitabili sovrapposizioni; gli spostamenti per invaso e per svaso si sono infatti verificati pressoché nella stessa direzione.

c) Concio $X X I X$. Il concio XXIX ha avu. to un comportamento nettamente distinto da quello dei conci XIV e XXIII. Ad una prima fase di spostamento angolare monte - valle (con leggera deviazio. ne a destra), corrispondente all'azione d'invaso, è seguito un periodo di stasi, con lievi spostamenti verso sinistra (fig. 27). Tali spostamenti si accentuarono nel settembre-ottobre 1950. Ai primi di novembre 1950 , il movimento angolare prese decisa direzione verso la spalla destra (fig. $27 \mathrm{bis}$ ), in coincidenza del movimento generale in questo senso, di cui si è accennato nel paragrafo 7 . Tale movimento, che durò fino alla fine del 1950, fu seguito da un periodo di stasi, finché iniziò il movimento che riportò il concio XXIX presso a poco nella posizione di svaso iniziale (fig. 28).

d) Spalla destra. I clinografi posti nella roccia, nei pressi della 


\section{Concio 14}

dal $6 \cdot V \cdot 1950$ al 26.VIII.1950

fala
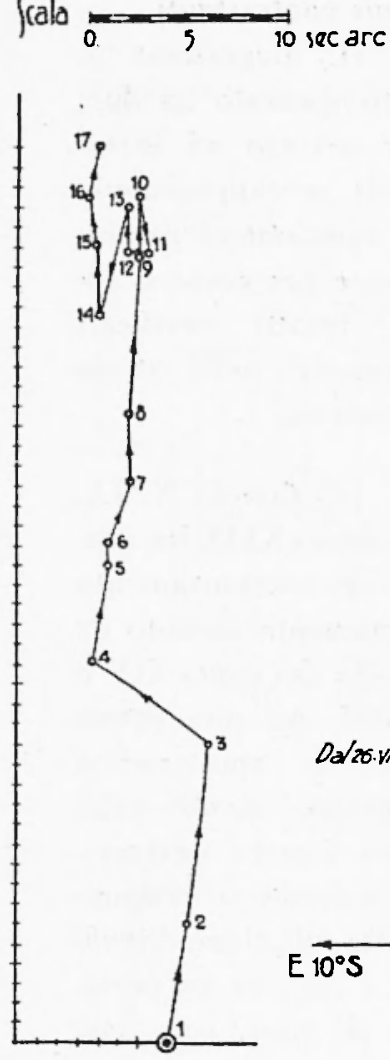

$\begin{array}{ll}1 & 6 \cdot v \cdot 1950 \\ 2 & 13 \text { (barreab) }\end{array}$

520

427

$53 . v 1$

610

$\begin{array}{lll}7 & 17\end{array}$

$\begin{array}{ll}8 & 24\end{array}$

9 I.ViI

108

$11 \quad 15$

$12 \quad 22$

$13 \quad 29$

145 . Vill

$15 \quad 12$

$16 \quad 19$

$17 \quad 26$

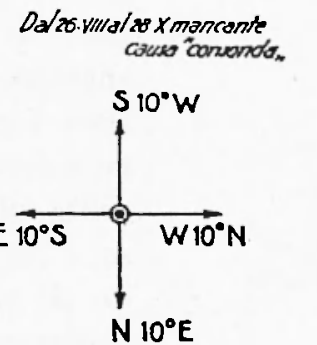

Fig. 30

La fig. 30 sintetizza i movimenti del concio XIV dall'inizio di un invaso alla fase di pieno carico, con sovrapposto l'effetto stagionale estivo (spinta a valle).

La fig. 30 bis, dopo una fase stazionaria, riassume l'effetto stagionale invernale, so. vrapposto all'effetto di svaso graduale e ad altre cause semiperiodiche di disturbo.

\section{Concio 14}

dal $28 \cdot x \cdot 1950$ al 16-v1·1953

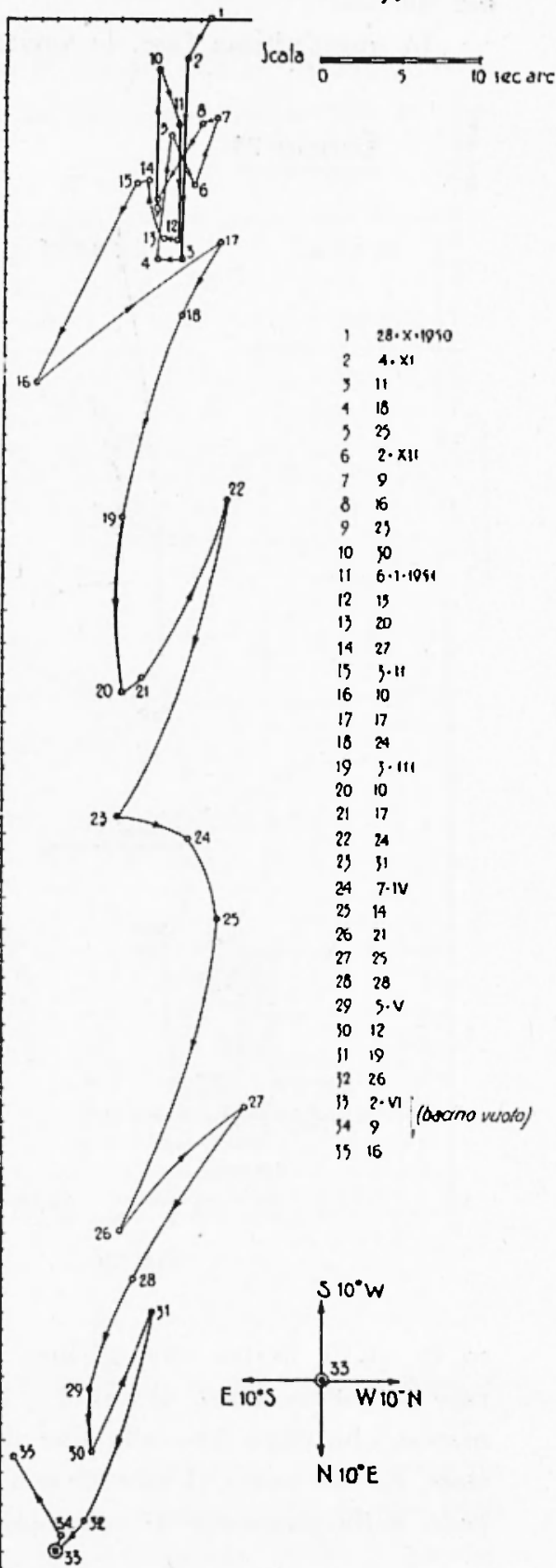

Fig. 30 bis 
diga, sulla spalla destra, hanno rivelato un comportamento alquanto singolare. Il moto angolare, nei primi mesi dopo l'invaso, si è verificato prevalentemente nel quadrante di $S E$ (fig. 26). Ai primi di Novembre, in corrispondenza dell'analogo movimento riscontrato nel concio XXIX, ha inizio un deciso movimento angolare nella direzione media $S 42^{\circ} E-N 42^{\circ} W$, eccezionalmente ampio nelle settimane 11-18,

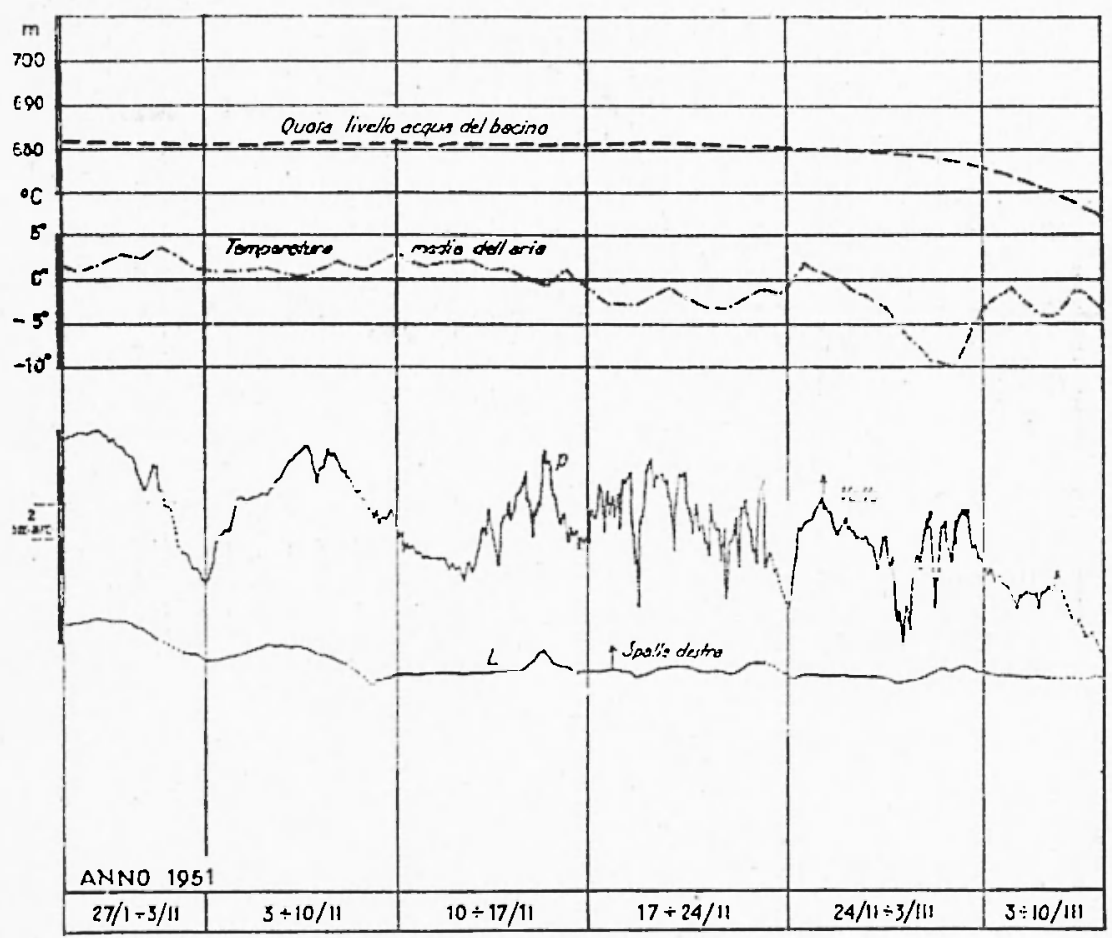

Fig. 31

18-25-XI-1950. 1l 24-II-1951 il moto si inverte e lo svaso completo trova la verticale apparente della postazione in spalla destra sensibilmente discosta dalla verticale apparente dell'inizio dell'invaso.

e) Riassumendo, da uno svaso (1950) al successivo (1951) il comportamento dei conci è stato il seguente. Il concio XIV ha compiuto un tragitto angolare di andata e ritorno pressoché nella stessa direzione (monte-valle, valle-monte), con lieve componente verso la spalla sinistra. Nel movimento di ritorno, il concio ha leggermente superato la posizione di partenza, "cadendo" verso il bacino. 


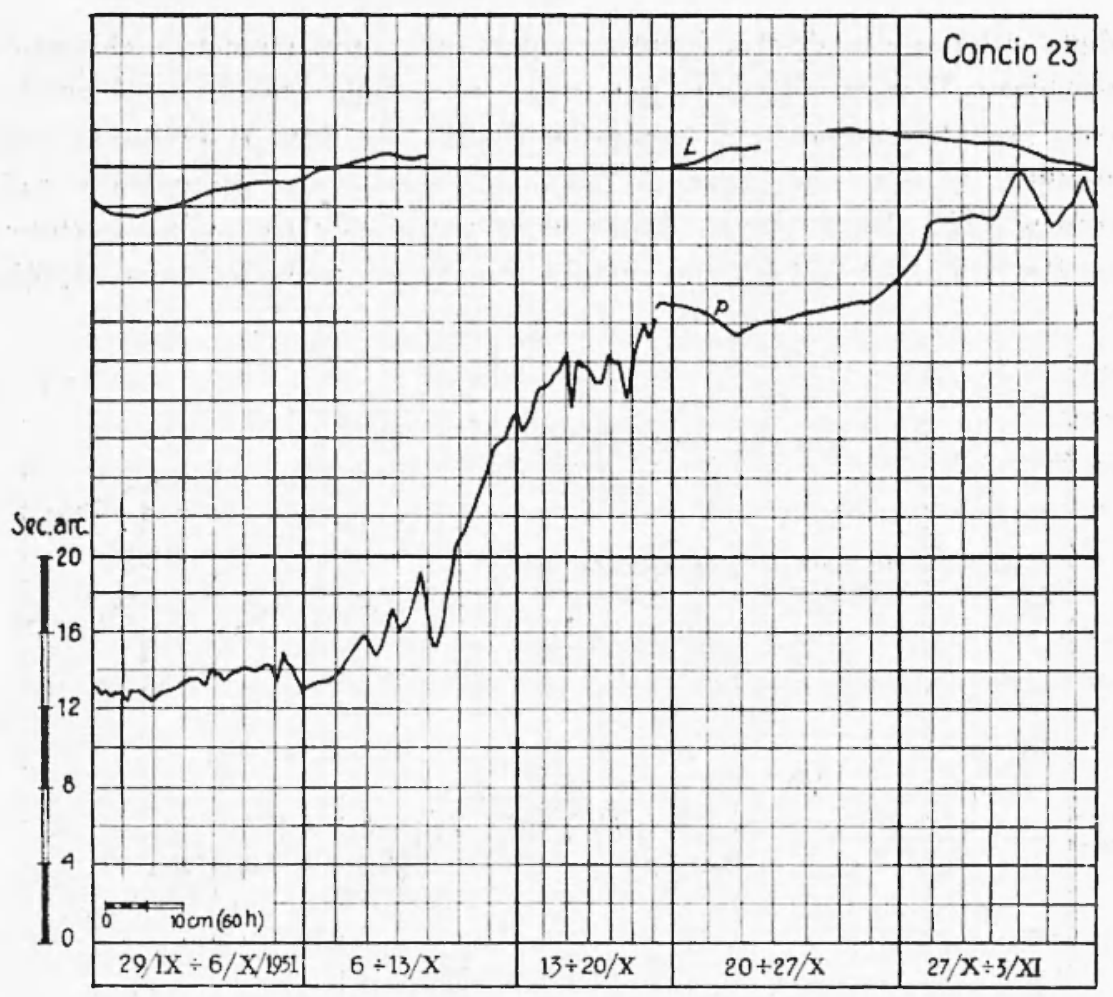

Fig. 32

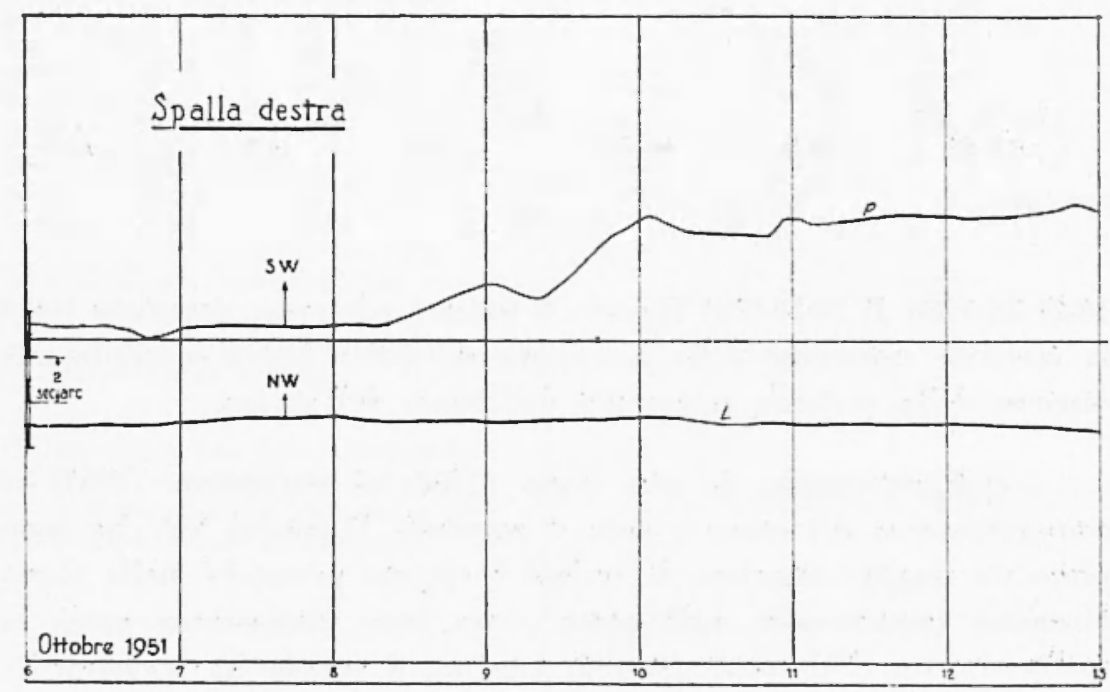

Fig. 32 bis 


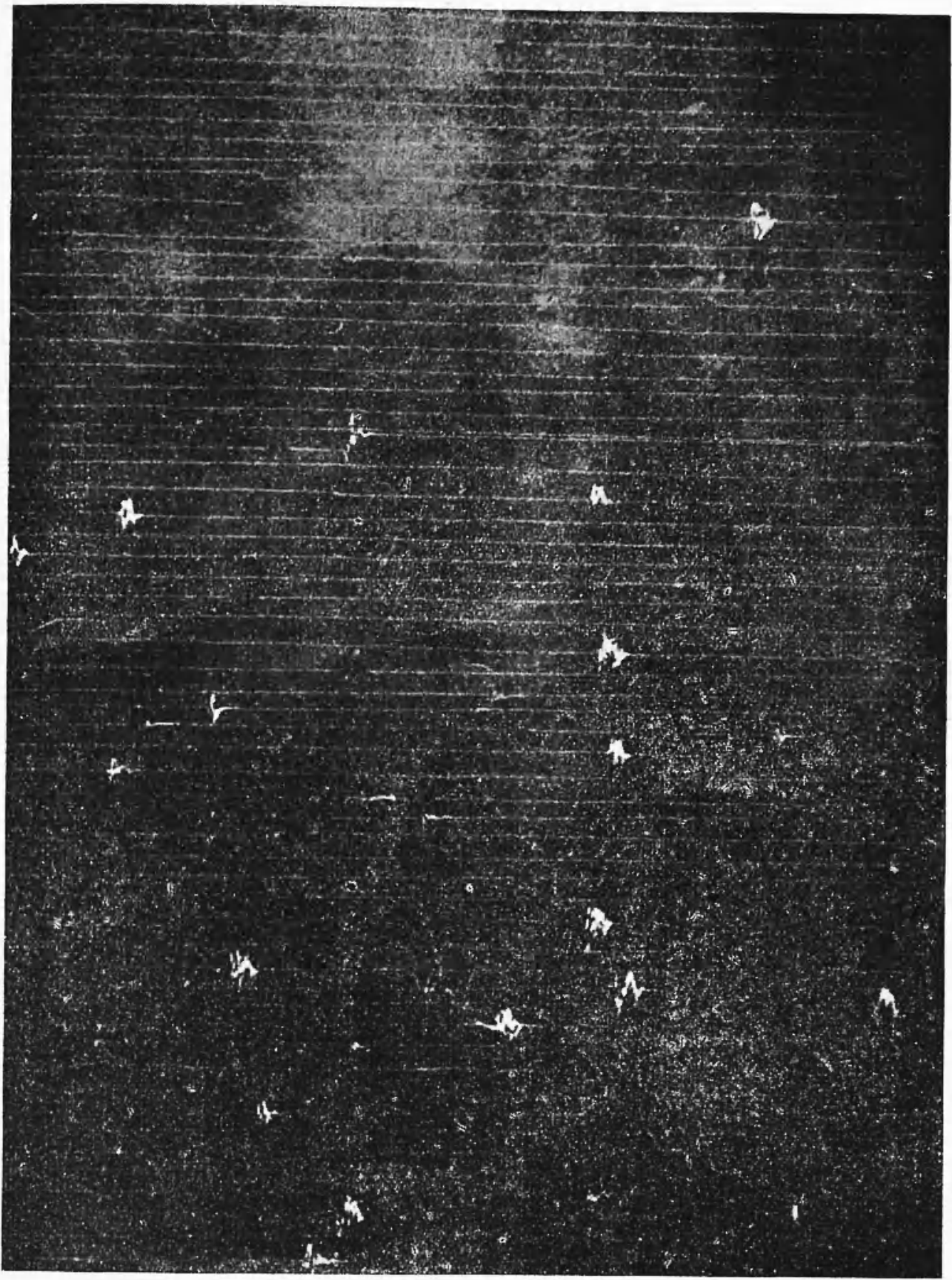

Fig. 33 
$\mathbb{n}$ concio XXIII ha avuto un analogo comportamento quasi esclusivo monte-valle, valle-monte con lieve componente verso la spalla destra. Lo svaso del 1951 trova il concio XXIII pressoché nella posizione di partenza.

II concio XXIX, dopo un lieve spostamento monte-valle, ha accusato un deciso spostamento angolare verso la spalla destra; anche il concio XXIX riprende, al termine del secondo svaso, presso a poco la primitiva posizione.

La forte componente dello spostamento a destra del concio XXIX Bi spiega col fatto che tale concio è prossimo alla sponda destra del fume: data la forma della diga (ad arco-gravità), è chiaro che una spinta centrale monte-valle, comporta per i conci laterali una sensibile componente verso le sponde.

La stazione clinografica sistemata in roccia nella spalla destra ha rivelato $i$ movimenti accennati in d). Al termine del secondo svaso. la verticale apparente differiva in modo netto dalla direzione primitiva. Il sistema roccioso interessato dalla postazione clinografica ha quindi subito una deformazione permanente; sia pure di lieve entiti. La spiegazione sembra ovvia. A differenza del calcestruzzo compatio dei conci, la spalla destra, cui la diga si appoggia, consiste di roccia fessurata, percorsa da vene d'acqua. Sotto la pressione dell'invaso, le piccole cavità vennero contratte, impedendo, al cessare della pressione, che il sistema roccioso riprendesse la primitiva posizione.

\section{9. - Confronto fra registrazioni clinografiche e registrazioni sismiche.}

Mi sono chiesto se le variazioni nell'intensità e nella frequenza delle piccole scosse registrate potevano avere qualche relazione con le analoghe variazioni nell'andamento dei fenomeni clinografici. Generalmente, si osserva una stretta relazione tra le più o meno rapide variazioni della verticale apparente e il numero e l'intensità delle scosse.

Le variazioni della verticale apparente corrispondono a flessioni, in un senso o nell'altro, dei conci della diga, entro i quali i clinografi funzionano.

Potrei citare numerosissimi esempi di una sorprendente corrispon. denza fra anormale attività sismica e attività clinografica fuori del comune.

Mi limiterò ad alcuni dei più significativi. 


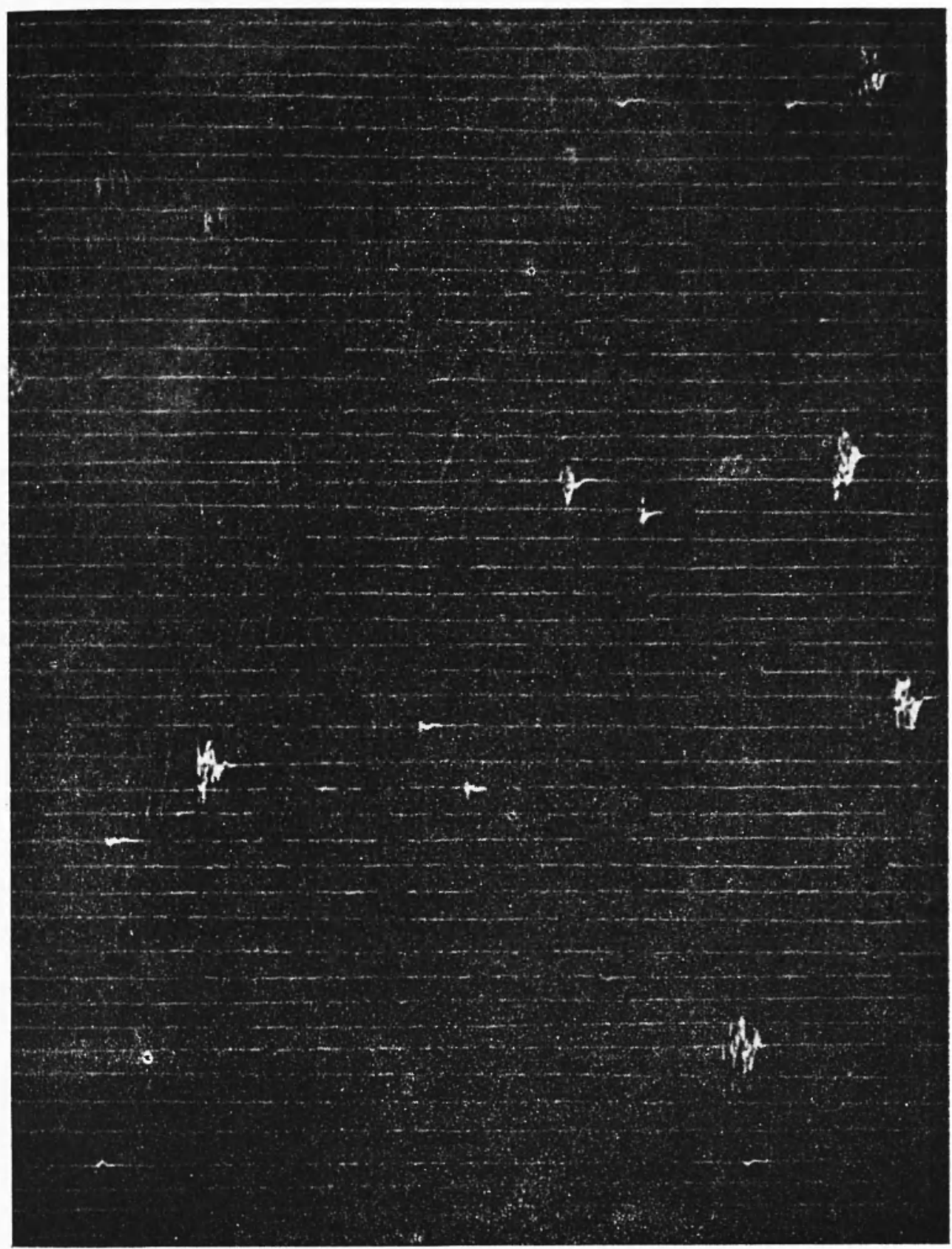

Fig. 34 
La notevole attività sismica, per numero e intensità di scosse, verificatasi dai primi di Febbraio al Maggio 1951 è strettamente legata ai lenti movimenti dei conci della diga, quali vengono rivelati dalle registrazioni dei clinografi. Dal Dicembre 1950 al Febbraio 1951 i moti dei conci sono di lievissima entità. Ai primi di Febbraio 1951, quasi bruscamente, specie sul lato sinistro della diga (com è provato dalle registrazioni clinograficbe del concio XIV) (fig. 30), inizia una serie di relativamente rapide variazioni angolari, con generale tendenza valle-monte. É notevole il fatto che, specie per il concio XIV, dette inclinazioni dei conci verso il bacino (in fase di svuotamento), non avvengono in modo continuo, ma sono alternate da movimenti di reazione in senso contrario. É proprio in questo periodo che il numero e l'inten. sità delle scosse si fa particolarmente notevole: la seconda delle serie di scosse analizzate si riferisce appunto agli inizi di Febbraio. Non v'è dubbio che l'accentuata attività sismica va attribuita alla complessità ed ampiezza dei moti dei conci della diga, che nelle loro rapide escursioni di andata e ritorno venivano a creare nel sottosuolo le condizioni favorevoli alle piccole fratture e susseguenti scorrimenti.

Osserviamo ancora che, nel periodo accennato, il concio XXIII - e, presumibilmente, anche $i$ conci limitrofi - accusa tutta una serie di movimenti rapidi, sovrapposti a quelli di più lungo periodo (fig. 31). Tali movimenti, naturalmente, hanno sottoposto le rocce entro cui sono infitti i conci, al tormento di continue brusche sollecitazioni, donde un'altra sorgente di piccoli scotimenti.

Un altro caratteristico periodo di eccezionale attività è quello legato alla fase di agitazione clinometrica, iniziatasi ai primi di Ottobre del 1951. Questa fase inizia, quasi bruscamente, il 6 Ottobre, sotto forma di una leggera flessione verso valle dei conci costituenti la parte destra della diga, com'è dimostrato dai clinogrammi dei conci XXIII, XXIX e della spalla destra, dove si è verificata una fuoruscita delle imagini dai registratori (fig. 32). Ebbene, proprio in quei giorni, con perfetta contemporaneità, si verifica una delle più eccezionali registrazioni di piccole scosse (figg. 9, 33, 34), d'un aspetto tutto particolare, che le contraddistingue da scosse di altra origine. Il movimento clinometrico, conseguente ad analogo movimento dei conci, riprende verso la metà di Ottobre e dura, quasi senza intervalli, fino al termine del 1951.

Collateralmente, permane intensa l'attività sismica, a testimonian- 


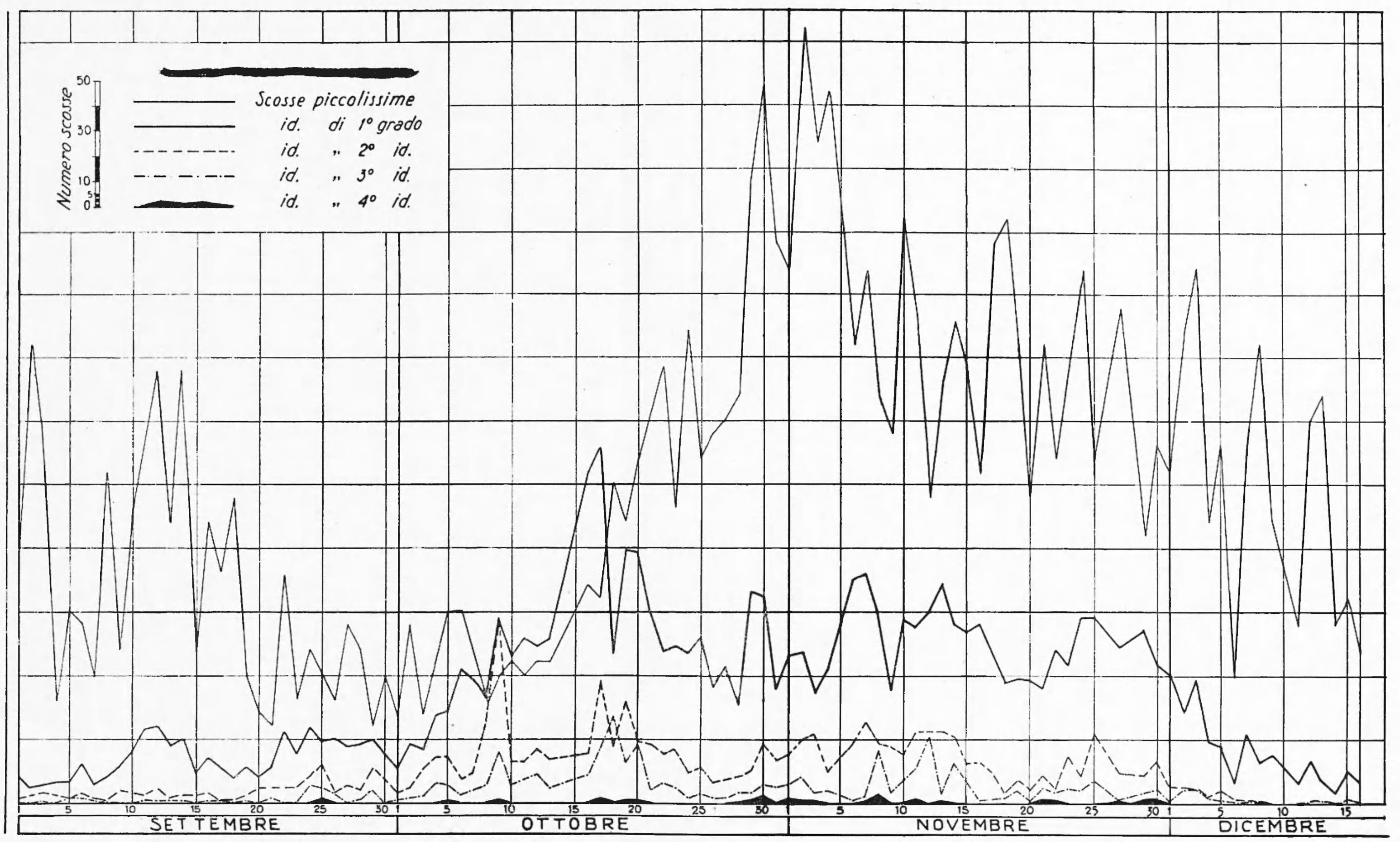

Fiz. ij 


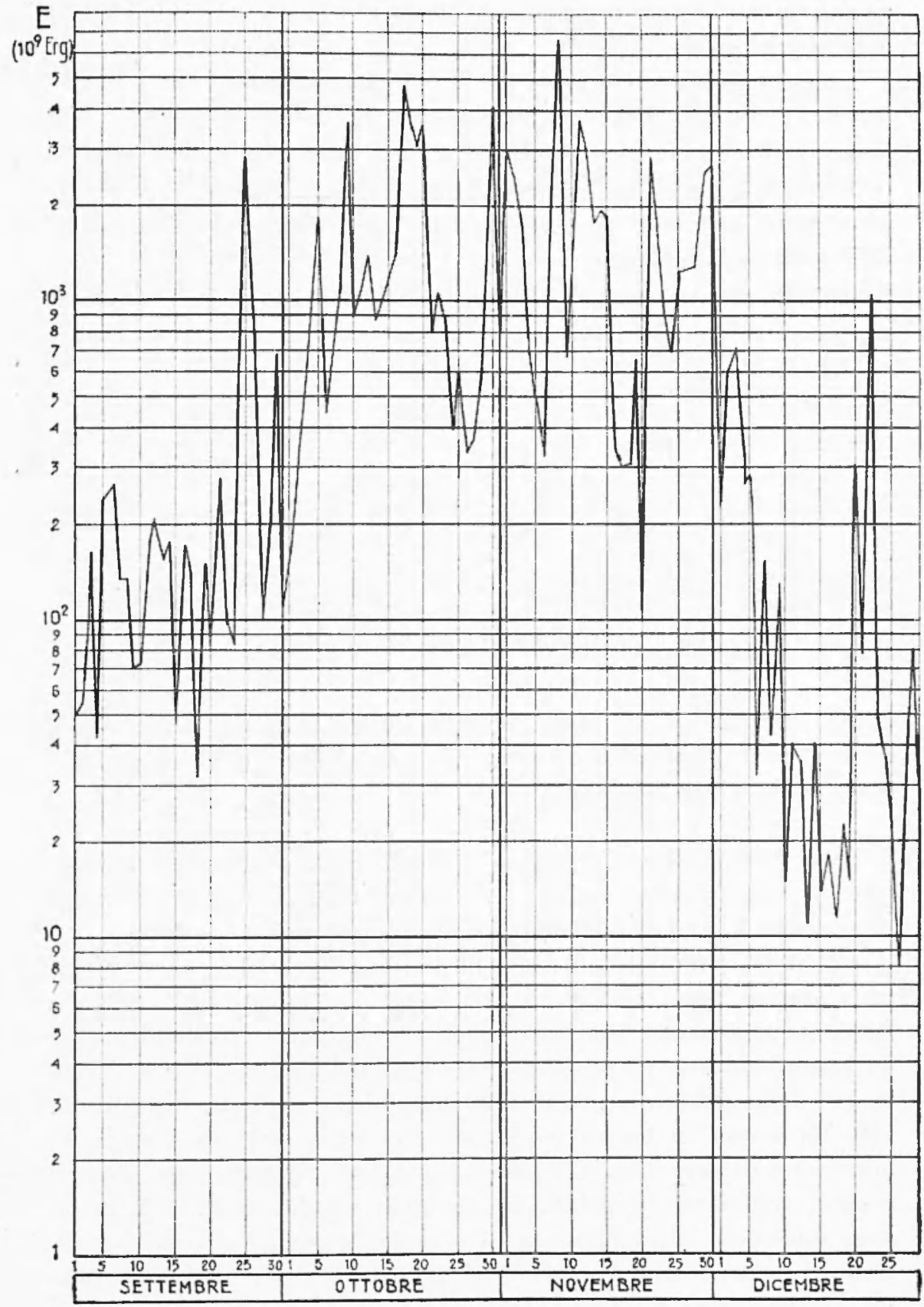

Fig. 36 
za dell'intimo legame fra lenti movimenti dei conci e piccoli bruschi moti sismici (figg. 35, 36, 37).

É qui opportuno osservare clie le scossette registrate hanno aspetto diverso, a seconda della loro provenienza. Se il loro epicentro è nell'interno del bacino, esse, anche se ampie, si smorzano rapidamente, limitandosi a poche oscillazioni, se invece si verificano alla base dei conci vicini alla stazione sismica, esse consistono in una lunga serie di rapidissime oscillazioni. Questo si spiega col fatto che il calcestruzzo dei conci (com'è stato provato nelle esperienze della diga del

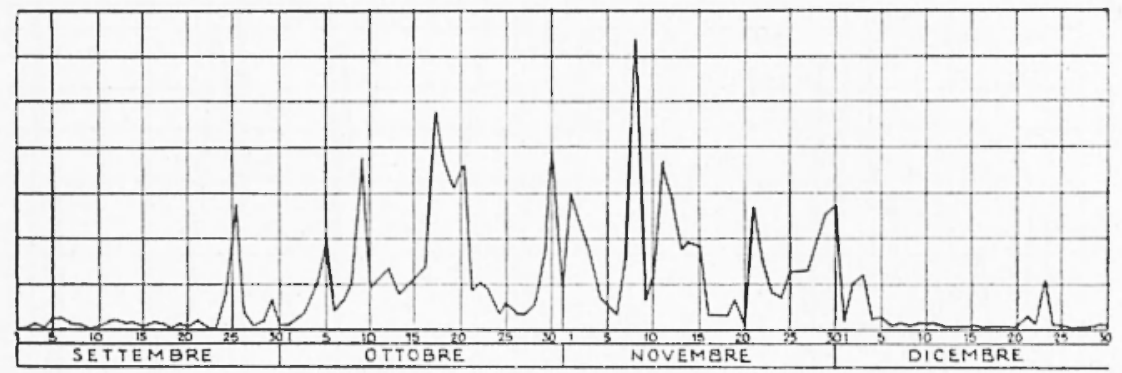

Fig. 37 - (In ordinata, un'uniti vale $10^{12}$ erg).

Lumiei) conduce ed esalta queste rapidissime oscillazioni, rispetto alle quali i conci hanno un comportamento che presenta qualche analogia con i rebhi di un diapason.

10. - Moti di diversa origine. -- I fotoclinografi registrano tutta una serie di movimenti - rapidi, lenti, periodici o aperiodici - la cui origine non è sempre facile da precisare. Darò qualche esempio.

Il 31 Dicembre 1950 la componente monte-valle del concio XXIII della grande diga cui si riferisce la maggior parte di queste osservazioni, sta registrando una lenta, lunga oscillazione, corrispondente ad un leggero aumento di pressione sulla diga, dalla parte del lago. Verso le $19^{\mathrm{h}}$ dello stesso giorno, il clinometro della su detta componente ( fig. 38) accusa un brusco movimento, nel senso corrispondente a diminuziene di pressione. Ciò costituisce l'inizio di tulta una serie di rapide oscillazioni irregolari, fra le quali figurano anche quelle di sesse uninodali (circa mezz'ora di periodo), miste ad altre aventi periodi di un'ora e più. Verso le 15,5 del 1-I-'5l, si ha un brusco moto del clinometro in direzione monte-valle: le rapide, irregolari oscillazioni durano fino alle $18 \mathrm{ca}$. del 2-I-'5]. 


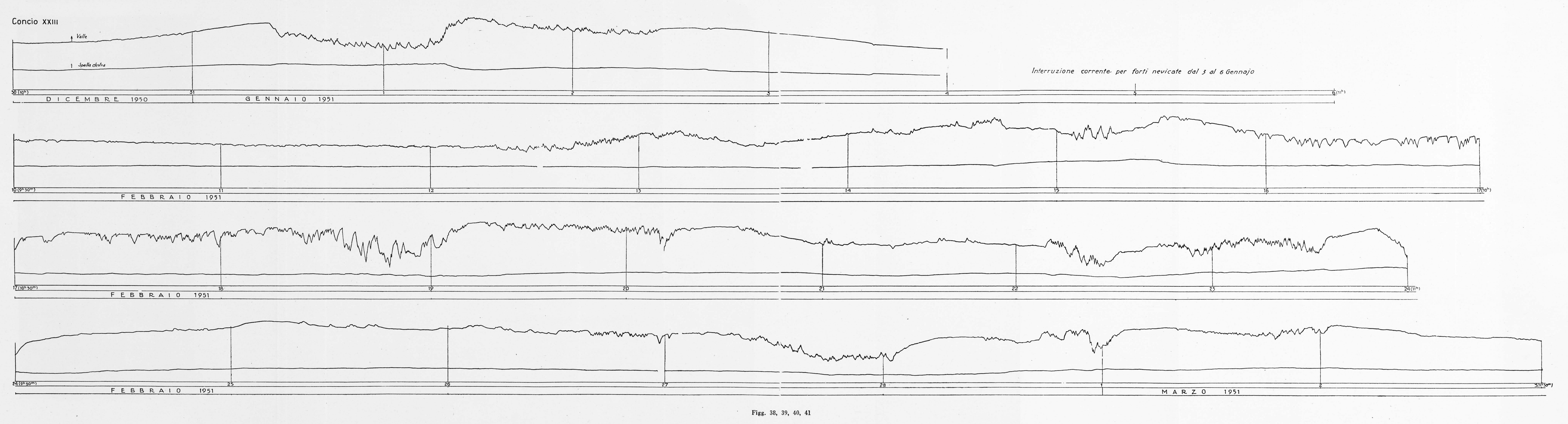




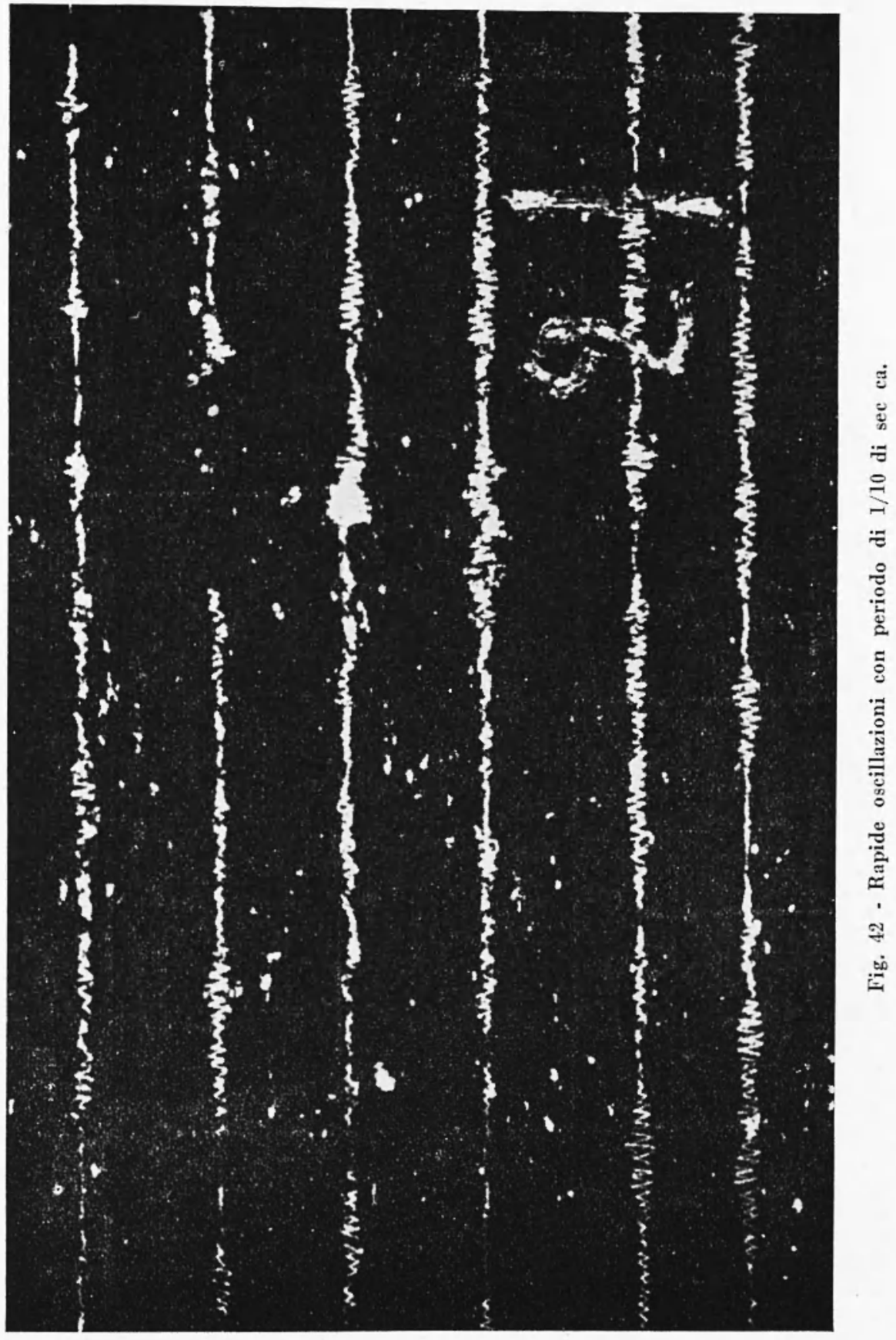


L'andamento della pressione atmosferica è stato del tutto normale; alla pressione atmosferica non è quindi da attribuire il feno. meno osservato, a meno che un treno di micropulsazioni atmosferiche, non registrate dal barografo, non abbia messo in moto il bacino idrico. Il vento soffiava da $N N W$, con velocità moderata. I movimenti registrati non vanno però attribuiti al vento, sia perché soffiando da quella direzione avrebbe dovuto provocare un accumulo d'acqua verso la diga, sia perché con quella velocità e da quella direzione soffia sovente, senza determinare $i$ movimenti in questione.

Di tali movimenti si hanno numerosi esempi, anche di molto vistosi.

Cito ancora dalle registrazioni ottenute nel concio XXIII, duve i clinografi hanno un registratore a lungo scorrimento, che consente una maggior risoluzione delle oscillazioni rapide. Particolarmente ricco di perturbazioni lente e rapide è stato il Febbraio 1951. Si osservi il tratto riprodotto dalla fig. 39 e più ancora, quello dato dalla fig. 40 , dove $\mathrm{i}$ movimenti rapidi, irregolari appaiono veramente notevoli.

Molto spesso si registrano contemporaneamente oscillazioni irregolari, a periodo molto più lungo - di otto, dieci giorni - e che durano dei mesi. Talvolta, tali oscillazioni sembrano in relazione con analoghe oscillazioni termiche (p. es. concio XIV): ma, in wenere. questo parallelismo non si riscontra (es. dall'8-I-195I, concio XXIII, e forse è più logico attribuirlo ad oscillazioni del blocco geodetico sopportante il tratto di diga interessato dai movimenti accennati.

I fotoclinografi registrano pure le piccole variazioni della verticale apparente, causate dalle oscillazioni libere (sesse) del lago: l'alternarsi dei massimi e dei minimi nelle ampiezze delle sesse, determina piccole variazioni di pressione sul fondo, che si tramutano, per la diga, in piccole variazioni della verticale apparente. Si Iratta, naturalmente, di oscillazioni clinografiche di piccola ampiezza, e di periodi molto al di fuori dei periodi propri d'oscillazione dei conci della diga. La sessa uninodale del lago ha infatti un periodo dell'ordine di 25 minuti primi (fig. 9-11).

Altre registrazioni si ottengono presso la stazione sismica della wrande diga in questione, registrazioni di interesse prevalentemente geofisico.

Noterò, fra esse, le numerosissime, estremamente rapide oscillazioni, registrate a centinaia in certe gionate del Dicembre 1951. Dette oscillazioni, aventi la forma complessiva di piccoli fusi, risultano di 


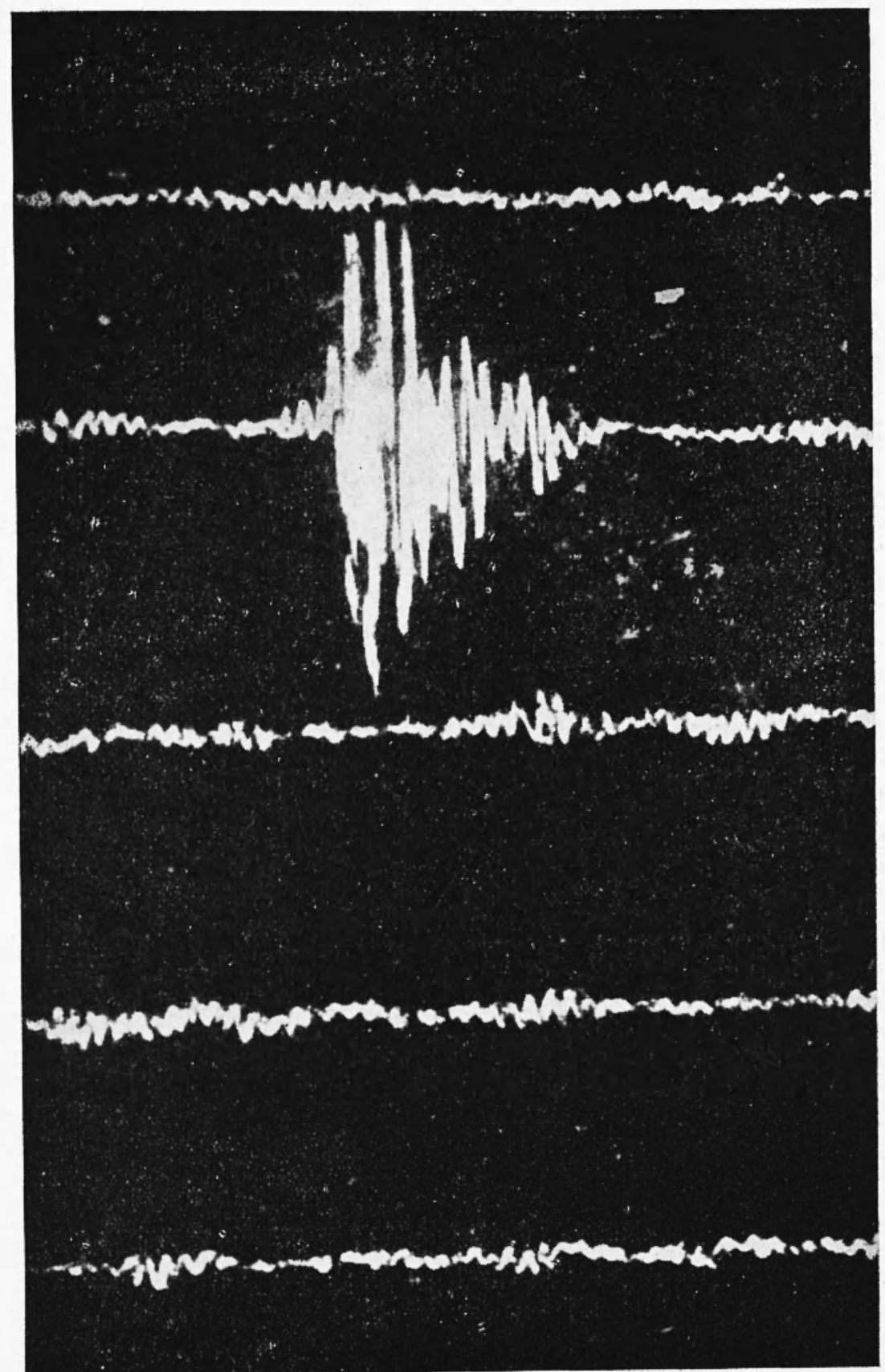

Fig. 43 - Agitazione microsismica con periodo di $1 / 10$ di sec ca; esempio di scosseltina. 


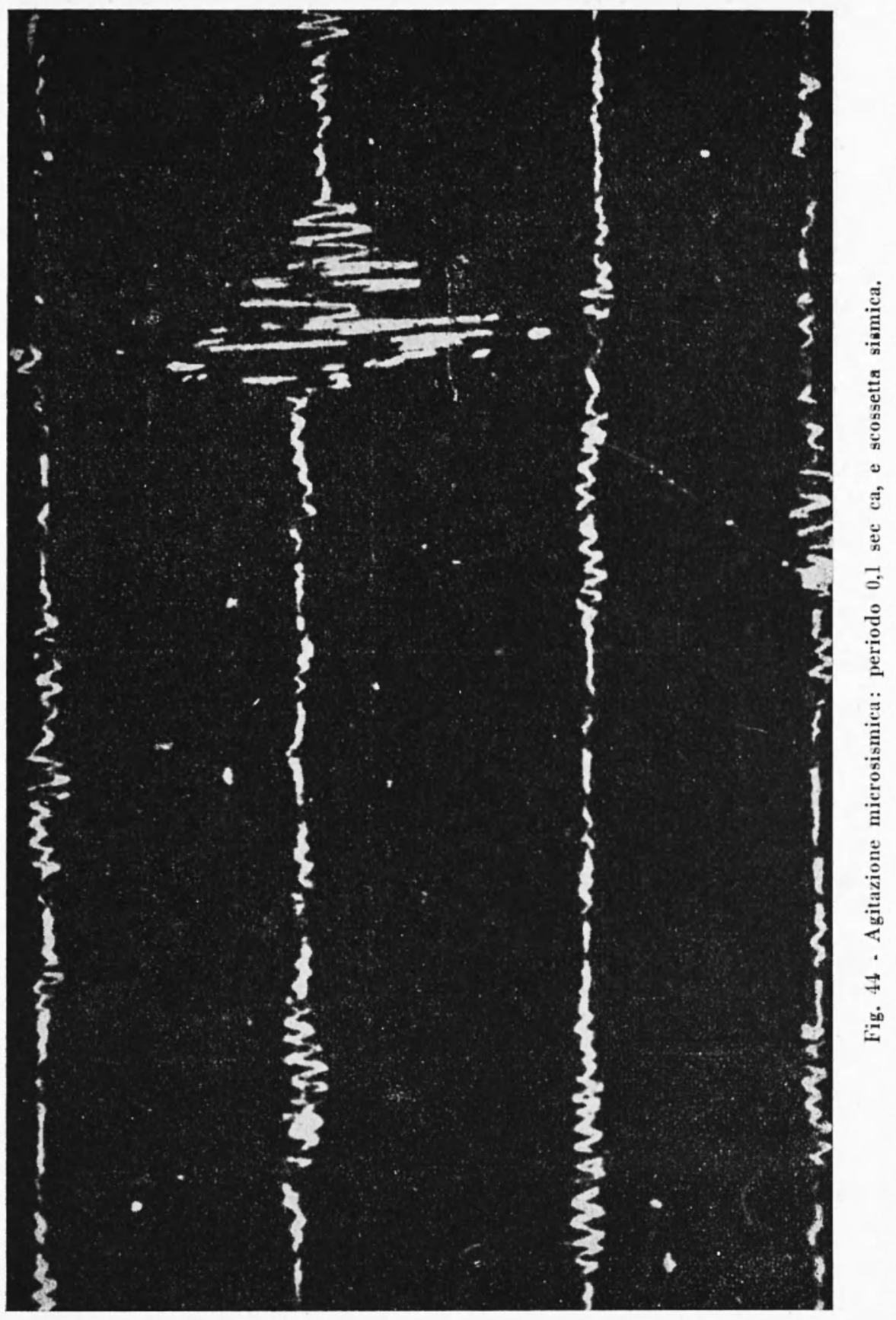


vibrazioni talmente rapide, da non essere possibile risolverle nemmeno ingrandendole. Non esito ad attribuire queste vibrazioni - registrate quando la stazione era nella sua provvisoria sistemazione in riva al lagro - a piccoli scotimenti comunicati alle rive delle crepe che, in certe giornate, si verificavano nel ghiaccio del lago gelato: è noto che le vilırazioni destate nel ghiaccio ("Biegewellen» dei tedeschi, "flexural waves» degli anglosassoni) sono generalmente di grandissima frequenza.

In altro fenomeno di carattere vibratorio e di notevole interesse greofisico, è la registrazione di una minutissima agitazione microsismica, di causa ignota, che dura per intere settimane. E noto che col nome di arritazione microsismica si suole indicare quelle perturbazioni, periodiche o no, che interessano la crosta terrestre e non sono di origine propriamente sismica. Particolarmente studiata, nei suoi aspetti scientifici e pratici, è l'agitazione microsismica, legata alle vicende atmosferiche e, sopra tutto, al transito dei cicloni sugli oceani e sui mari interni. Tale agitazione, costituita da gruppi di oscillazioni con periodi varianti da 1 a 12 sec., a seconda della distanza del nucleo perturbante e alle condizioni geologiche degli strati attraversati, viene registrata in tutte le stazioni sismiche del mondo - dove più, dove meno - e presenta i suoi massimi durante la stagione invernale.

Il tipo d'aqritazione di cui qui si tratta non rientra nella specie accennata. D'altronde, non può neppure essere attribuita al traffico, data la distanza delle grandi città, delle grandi linee di comunicazione e delle condizioni in cui si manifesta. Mi propongo di dedicare ad essa la mia attenzione, allo scopo di scoprire - se è possibile le cause di questa minutissima agitazione (come risulta dalle figg. $12,43,44$ essa ha un periodo dell'ordine di $1 / 30$ di sec.). E essa in relazione con piccoli movimenti orogenetici in atto? $\mathrm{E}$ quanto le ricerche clue ci proponiamo di fare potranno - speriamolo - chiarire.

Roma - Istituto Nazionale di Geofisica - Luglio 195:3.

\section{RIASSUNTO}

Si espongono brevemente alcuni dei risultati raggiunti in un primo periodo d'osservazione geofisica (in particolare sismica e clinografica). di una grande diga di sbarramento per bacino idroelettrico. Da quanto viene esposto, risulta chiaro l'interesse di tali osservazioni con- 
tinuate. Interesse scientifico, per $i$ nuovi elementi che si possono trarre circa il comportamento di una grande diga, nei confronti della roccia a cui è ancorata e delle spinte cui viene sottoposta dalla parte del bacino, e per aver messo in evidenza che molte cause perturbanti non hanno relazione alcuna con la scienza delle costruzioni, essendo di pretta origine geofisica (come $i$ movimenti dei blocchi geodetici). Interesse pratico non meno elevato, perché da una continua, pronta, sensibilissima azione di controllo, quale può essere quella esercitatn da speciali sismografi e da fotoclinometri presso una grande diga, posscno essere tempestivamente seguite eventuali, anche minime, flessioni e comunque evitati danni maggiori.

\section{SUMMARY}

Some of the results obtained in a first period of geophysical observation (in particular, seismic and clinographic) of a vast retention drm for a hydroelectric reservoir are briefly explained here. From the time that these results were first made known, the interest has been cleat in such continuous observations. Of scientific interest are the following: any new information that one can extract with respect to the behavior of a large dam, the comparison of the rocks to which it is secured, and knowledge of the forces to which it is subjected on the" part of the reservoir, and also that many perturbing causes have no" relation to the science of construction, being of merely geophysicral origin (such as the movements of geodetic crustal blocks). Of prastical interest, not less important because they give a continuous, prompl. and very sensitive means of control, are the measurements given by special seismographs and photoclinometers placed near a great dam. Other measurements on minima and flexures can quite possibly be car. ried out with the avoiding of large scale damage.

\section{BIBLIOGRAFIA}

(1) Calor P. Attivitì sismicu in Italia nel decennio 1930.39. In Appendice: Fdi. lizia asismica e reazioni degli edifici e del sottosuolo alle sollecilazioni sismiche. Felice Le Monnier, Firenze 1942 (137 pagg., 42 figg. nel testo e 72 tav. fuori testo).

(2) Calor $\mathrm{P}_{m}$ Interpretnzioni geofisiche di misure geodetiche. Annali di Geofi. sica, IV (1951).

(3) Calor P., Il pendolo orizzontole come clinometro. Annali di Geofisica. III (1950). 